NBER WORKING PAPER SERIES

\title{
INDIVIDUAL PREFERENCES, ORGANIZATION, AND COMPETITION IN A MODEL OF R\&D INCENTIVE PROVISION
}

\author{
Nicola Lacetera \\ Lorenzo Zirulia \\ Working Paper 17031 \\ http://www.nber.org/papers/w17031
NATIONAL BUREAU OF ECONOMIC RESEARCH
1050 Massachusetts Avenue
Cambridge, MA 02138

May 2011

We are grateful to Ajay Agrawal, Kevin Boudreau, Ramon Casadesus-Masanell, Erika Färnstrand Damsgaard, Ramana Nanda, Heather Royer, Mark Schankerman, Justin Sydnor, Neil Aaron Thompson, Henry Sauermann, session attendants at the 2010 Harvard Business School Strategy Conference, the 2010 DRUID Conference, the EEA 2008 Meetings, the 2008 REER Conference at Georgia Tech, and the EARIE 2007 Meetings, and seminar participants at Boston University, University of Bologna, Bocconi University, University of Naples Federico II for their comments and suggestions. Tina Chen provided excellent research assistance. The views expressed herein are those of the authors and do not necessarily reflect the views of the National Bureau of Economic Research.

NBER working papers are circulated for discussion and comment purposes. They have not been peerreviewed or been subject to the review by the NBER Board of Directors that accompanies official NBER publications.

(C) 2011 by Nicola Lacetera and Lorenzo Zirulia. All rights reserved. Short sections of text, not to exceed two paragraphs, may be quoted without explicit permission provided that full credit, including $\odot$ notice, is given to the source. 
Individual Preferences, Organization, and Competition in a Model of R\&D Incentive Provision Nicola Lacetera and Lorenzo Zirulia

NBER Working Paper No. 17031

May 2011

JEL No. L1,L22,M12,O31,O32

\begin{abstract}
$\underline{\text { ABSTRACT }}$
Understanding the organization of R\&D activities requires the simultaneous consideration of scientific workers' talent and tastes, companies' organizational choices, and the characteristics of the relevant industry. We develop a model of the provision of incentives to corporate scientists, in an environment where (1) scientists engage in multiple activities when performing research; (2) knowledge is not perfectly appropriable; (3) scientists are responsive to both monetary and non-monetary incentives; and (4) firms compete on the product market. We show that both the degree of knowledge spillovers and of market competition affect the incentives given to scientists, and these effects interact. First, high knowledge spillovers lead firms to soften incentives when product market competition is high, and to strengthen incentives when competition is low. Second, the relationship between the intensity of competition and the power of incentives is U-shaped, with the exact shape depending on the degree of knowledge spillovers. We also show that the performance-contingent pay for both applied and basic research increases with the non-pecuniary benefits that scientists obtain from research. We relate our findings to the existing empirical research, and also discuss their implications for management and public policy.
\end{abstract}

Nicola Lacetera

University of Toronto

Rotman School of Management

105 St. George Street, Room 265

Toronto, ON M5S 2E9

and NBER

nicola.lacetera@utoronto.ca

Lorenzo Zirulia

University of Bologna

Department of Economics

Strada Maggiore, 45

Bologna, Italy

lorenzo.zirulia@unibocconi.it 


\section{Introduction}

The management of scientific workers and the design of effective incentives for them are considered key determinants of competitive success, ${ }^{1}$ but present numerous challenges for companies. A major organizational decision concerns whether to provide high-powered incentives based on the scientists' performance, or to soften incentives instead and let the researchers' quest for reputation drive their effort. Another difficulty is how to measure performance in the first place, since research is a complex activity with no necessarily immediate returns (Holmstrom, 1989). A further set of issues concerns how the characteristics of the markets where a company operates, and in particular the level of competition and knowledge appropriability, affect the type and strength of incentives. Understanding how companies motivate scientific workers is of importance also for policy makers. Key industrial policy questions concern how to design competition laws and intellectual property regimes that elicit incentives to innovate for firms, and therefore affect the types of incentives companies offer to their researchers, while not curbing the dissemination of knowledge.

In fact, these issues point to broader challenges for both scholars and practitioners. All major organizational problems require the considerations of multiple levels of analysis: individual characteristics such as talent and tastes (Sauermann et al., 2010; Stern, 2004); organizational capabilities and structure, including the incentive system (Henderson and Cockburn, 1994; Holmstrom, 1989; Holmstrom and Milgrom, 1994); and the characteristics of the relevant industry, in particular the competitive pressure (Porter, 1980; Raith, 2003; Schmidt, 1997; Turner et al., 2010). While the importance of all of these dimensions is often recognized, research that tries to integrate them in one framework is limited.

In this paper, we develop a model to show that not only all of these dimensions affect the determination of incentives to company scientists, but that these different factors interact in interesting ways. The model is developed in Section 2, and includes four key aspects. First, scientists engage in multiple, different activities (Cockburn et al., 1999). Second, the outcome of research activities, knowledge, is only imperfectly appropriable (Arrow, 1962; Spence, 1984). Third, while scientists are responsive to the provision of monetary incentives, they also care about non-material outcomes, such as their reputation among peers (Dasgupta and David, 1994; Merton, 1973). Fourth, the provision of incentives to scientists, and to all workers in general, is likely to depend on the conditions that a firm faces in the product market, such as the intensity of competition (Raith, 2003; Schmidt, 1997). In the model, two firms compete in an industry by offering differentiated products, and design incentives for their scientists (simplified to be a single agent per firm) to invest in cost-reducing research. Scientists engage in two types of efforts. The first kind of effort - which we call applied (or proprietary) research - does not provide non-pecuniary benefits to the scientists and does not generate knowledge spillovers to the rival firm; the second kind of effort - we call it basic (or open) research - provides non-pecuniary benefits to scientists but spills over to the rival firm. The firm's

\footnotetext{
${ }^{1}$ Andersson et al. (2009), Dennis (1987), Garnier (2008), Henderson and Cockburn (1994), Lamoreaux and Sokoloff (1999), Lerner and Wulf (2006), Sauermann and Cohen (2008), Zucker and Darby (1995).
} 
owners offer a wage contract to the scientists contingent on observable outcomes. The outcomes can include, for example, patents and scientific articles.

In Section 3 we discuss the results of the model, characterizing the optimal incentive contract for the scientists. The first set of results highlight how the provision of incentives for basic and applied research depends not only on the intensity of competition and the degree of knowledge spillovers, but also crucially on the interaction between these two environmental conditions. High knowledge spillovers do not necessarily reduce the incentives to perform research: if competition is low, then firms provide high-powered incentives for both basic and applied research, since their dominant position in the product market reduces the negative effects of spillovers while allowing firms to enjoy each other's produced knowledge. With high competition, not only do we derive that incentives for basic research effort decrease as spillovers become more pervasive; we also show that it is optimal to mute incentives for applied research effort, even if it does not generate spillovers. In turn, the impact of product market competition on the strength and direction of R\&D incentives depends on the degree of knowledge spillovers. If knowledge spillovers are low, firms provide the strongest incentives for basic and applied research both when they face very little competition (since cost reduction through $\mathrm{R} \& \mathrm{D}$ has a bigger absolute impact on profits), and when competition is very high (for competitive pressure makes any small cost reduction a proportionally large one, because profits are lower). Thus, the relationship between the intensity of competition and the power of incentives to scientists is U-shaped. In contrast, when there are high levels of spillovers, the strength of incentives is decreasing in the intensity of competition. A further implication of these findings is that incentives for basic and applied research are complementary only if either the level of product market competition or the degree of spillovers is low.

The second set of results concern the impact of a scientist's non-monetary motivation to perform basic research, or taste for science, on her pay scheme. The response of scientists to steeper incentives is stronger when they also have high intrinsic motives to perform basic research. As a consequence, companies optimally provide stronger incentives to intrinsically motivated scientists, both for basic research and applied research, even if the latter does not generate non-monetary benefits to the scientists. We show, in contrast, that a trade-off can occur between the fixed component of pay and non-monetary rewards.

An implication for empirical research is that studies of the determinants of incentives to scientists need to account for such environmental conditions as the degree of product market competition and of appropriability of knowledge, and need to analyze separately different components of wages, e.g. fixed and contingent pays, since they might respond differently to certain individual or environmental changes. In describing the model's implications in Section 3, we also interpret a number of existing empirical studies in the light of our findings.

The model in this paper is, to our knowledge, the first one to analyze the effects of product market characteristics on incentives for effort (in research activities) where effort is multi-dimensional and the agents have preferences or tastes for certain activities. The building blocks of the model 
here have been established by an extensive literature; we show that the interaction between these blocks is crucial for our results. There is, in particular, a vast literature investigating the relationship between competition and managerial efficiency (e.g., Raith, 2003; Schmidt, 1997) and between competition and innovation (among the most recent contributions, see Sacco and Schmutzler, 2009; Schmutzler, 2010; and Vives, 2008). Baggs and de Bettignies (2007), moreover, link these two streams of literature by developing a model where they isolate the agency effect of competition from the direct pressure effect, which is present independent of agency costs. Some papers consider also the presence of knowledge spillovers in R\&D investments (Spence,1984; Qiu,1997). ${ }^{2}$ We contribute to these studies by showing that the impact of each of these two factors crucially depends on the other. Furthermore, a few papers have developed principal-agent models where agents are intrinsically motivated. Murdock (2002) considers a model where agents also have intrinsic motivations for the completion of projects, but the principal may prefer not to implement some of these projects if they have negative expected financial returns. Implicit contracts where the principal commits to implement the projects preferred by the agent may be socially superior and are more likely to be chosen by a principal when the agent's intrinsic motivation is higher (see also Manso, 2010). ${ }^{3}$ Murdock's model, therefore, studies the relationship between decision right allocation and the intrinsic motivation of agents, while our model analyzes the shape of the optimal incentive contracts as it responds to non-monetary motives of agents. Besley and Ghatak (2005) develop a model of matching with intrinsically motivated agents and show that monetary and non-monetary incentives are substitutes. In their model, the reward of the principal is unaffected by the agent's intrinsic motivation, thus the principal exploits intrinsic motivation to save on the cost of highpowered incentives. In our model, the taste for science, through its impact on the desire to perform basic research, directly impacts the principal's payoff, thus leading to complementarity. Finally, Banal-Estañol and Macho-Stadler (2010) study the time allocation problem among different activities of a researcher who responds to both financial and scientific incentives, and show that higher financial incentives can lead a scientist to opt for riskier projects. Their study, however, abstracts from the analysis of the impact of knowledge appropriability and product market competition.

Section 4 explores the managerial and policy insights from our results. In highlighting the interaction between the conditions in the product market and the ease of transmission of knowledge, our results inform $R \& D$ managers on the importance to look at their company's position in the product market and at the knowledge appropriability conditions for different types of activities when designing their internal incentive schemes. R\&D managers, moreover, need to consider the different degrees of interest for monetary pay and for their reputations of their scientists. Scientists who are more eager to maintain their links to the scientific community even when employed by a firm, and are allowed to do so, are not necessarily "cheap." Instead, these are the scientists who are given more powerful incentives for the performance of both basic and applied research. As for

\footnotetext{
${ }^{2}$ See also De Bondt (1997) for a survey.

${ }^{3}$ Manso's model also considers intertemporal research contracts, while we abstract from dynamic considerations.
} 
public policy, our analysis implies that IP protection rules should be determined in relation to the level of competition of each industry and that, in particular, antitrust legislation and IP protection are complementary instruments. For example, in industries where IP protection is very strong, competition on the product market should be particularly favored.

Section 5, finally, offers concluding remarks.

\section{The Model}

In this section, we present the basic structure of our model. We first describe the characteristics and key variables and parameters defining the competitive environment, the incentive system, and the individual preferences of scientists. We then discuss and motivate in more detail our assumptions. Finally, we solve the model and determine the optimal incentive scheme for scientists. All proofs are gathered in the Appendix.

\subsection{Setup}

The model is built as a four-stage game whose timing is represented in Figure 1 and whose detailed description follows.

The competitive environment Two firms, $i$ and $j$, compete on the market by choosing the quantity they produce (Cournot competition). The firms' objective is to maximize their expected profits. The inverse demand schedule for the product of firm $i$ can be represented as follows (the setup for firm $j$ is symmetrical to that for firm $i$ as described here):

$$
p_{i}=A-q_{i}-\lambda q_{j}
$$

where $p_{i}$ is the price, $q_{i}$ is the quantity, and $\lambda \in[0,1]$ is a parameter indicating the intensity of competition with the rival firm $j$. The limit case of $\lambda=0$ reflects the firms operating as monopolists in separate markets. The opposite limit case of $\lambda=1$ represents the highest level of competition in this setting, with the two rivals supplying homogenous products. ${ }^{4}$ Firms bear production costs that can be represented as follows:

$$
T C_{i}=c_{i} q_{i}
$$

In (2), $T C_{i}$ stands for total costs. Therefore, $c_{i}$ is the marginal cost of production. The marginal cost can be reduced through the performance of research activities. Specifically, the firm can hire a scientist who exerts research effort before competition in the product market occurs. Effort has two dimensions: applied $\left(e_{i}^{A}\right)$ and basic $\left(e_{i}^{B}\right)$ research. We assume that effort is unverifiable. The

\footnotetext{
${ }^{4}$ As shown by Singh and Vives (1984), the demand function in (1) can be obtained by the maximization problem of a representative consumer with utility function: $U\left(q_{i}, q_{j}\right)=A\left(q_{i}+q_{j}\right)-\frac{\left(q_{i}^{2}+2 \lambda q_{i} q_{j}+q_{j}^{2}\right)}{2}$.
} 
marginal cost (and profits) will be unverifiable, or non-contractible, too. The relationship between effort and marginal cost for firm $i$ is as follows:

$$
c_{i}=c-e_{i}^{A}-e_{i}^{B}-\beta e_{j}^{B},
$$

where $c$ is a constant and $\beta$ is in the interval $[0,1]$. In addition to the efforts of its own scientist, firm $i$ can have its marginal costs further reduced by the effort in basic science performed by firm $j$, because basic research is not perfectly appropriable and its result can spill over also to firm who do not perform it. The size of the parameter $\beta$ determines the degree of knowledge spillovers.

The incentive scheme In order to compensate the scientist for her (costly, as described below) effort and to influence the scientists choice of the type of effort, the firm offers the scientists a wage $w_{i}$ that takes the form of an incentive contract. The non-contractibility of marginal costs and profits does not allow the scientist's wage to be contingent, say, directly on profits. ${ }^{5}$ The firm proposes an incentive contract on other measures that are verifiable. We consider two verifiable signals, $X^{A}$ and $X^{B}$, that are functions, respectively, of $e^{A}$ and $e^{B}$, and of stochastic shocks. Patents (or proofs of concept) and academic papers can be considered, as expressed in numbers or value, as observable measures of the two types of effort, respectively. Large-sample analyses as well as case studies report that many companies, especially in research-intensive industries, base the incentive schemes for scientists on direct outcomes of their research activities, let their researchers publish and, more generally, participate in the activities of their community of peers outside the company's (and the industry's) boundaries, and even reward scientists on the basis of their standing in the scientific community (Cockburn et al., 1999; Garnier, 2008; Gittelman and Kogut, 2003; Henderson and Cockburn, 1994; Hicks, 1995; Huckman and Strick, 2010; Liu and Stuart, 2010). Define:

$$
\begin{aligned}
& X_{i}^{A}=e_{i}^{A}+\varepsilon_{i}^{A}, \\
& X_{i}^{B}=e_{i}^{B}+\varepsilon_{i}^{B},
\end{aligned}
$$

where $\varepsilon_{i}^{A}$ and $\varepsilon_{i}^{B}$ represent random shocks with zero mean. The wage schedule firm $i$ proposes to scientist $i$ takes a linear form:

$$
w_{i}=\alpha_{i}^{0}+\alpha_{i}^{A} X_{i}^{A}+\alpha_{i}^{B} X_{i}^{B},
$$

where the variables $\alpha_{i}^{0}, \alpha_{i}^{A}$ and $\alpha_{i}^{B}$ are under the control of the firm.

The wage contract is offered simultaneously by the two firms to their own scientist, before effort is provided, and the scientist is paid at the realization of the performance measures, which can be assumed to occur before the firms compete on the market.

\footnotetext{
${ }^{5}$ The non-contractibility of costs and profits can be considered as a natural assumption especially in the context of small, entrepreneurial firms, where monitoring costs are high and most financial information is not public. In addition, we model costs as a deterministic function of efforts. An alternative formulation would be to model costs as random functions of efforts, while assuming they are contractible, as in Raith (2003). In this case, we could consider also contracts contingent on profits as in Hart (1983). Alternatively, one could include in the model the choice of the observables on which to base the contract, as in Piccolo et al. (2008).
} 
The individual preferences The (risk-neutral) scientists derive utility both from monetary rewards, and from the possibility to engage in basic research activities. In addition to caring about money, scientists therefore have a "taste for science." Effort costs are quadratic and separable. The utility function of a scientist hired by firm $i$ is:

$$
U_{i}=w_{i}+\rho e_{i}^{B}-\gamma\left[\frac{\left(e_{i}^{A}\right)^{2}}{2}+\frac{\left(e_{i}^{B}\right)^{2}}{2}\right]
$$

where $\rho>0$ is the degree of taste for science and $\gamma>0$ is a parameter inversely related to the productivity of applied and basic research. The scientist's reservation utility is denoted with $\bar{u}$.

\subsection{A discussion of the model's structure}

Before we solve the model, some observations on its assumptions and robustness to alternative specifications are in order. First, in the model firms compete à la Cournot. An alternative specification would consider Bertrand competition; this raises the question of whether price competition would lead to different results. We have, in fact, analyzed a version of the model with price competition. The results, available upon request, can be summarized as follows. Cournot competition is conducive to higher applied and basic research than Bertrand competition, ceteris paribus, consistent with previous comparisons made for one-dimensional effort (Qiu, 1997). With Cournot competition, higher investments in R\&D make the firm "tougher" (bigger) in the market and this discourages its rival's sales (a strategic effect). With price competition, a firm's R\&D lowers costs and induces a rival to cut its price, which is detrimental to both. As a consequence, the type of competition does affect the level of the incentive piece rates. This difference notwithstanding, almost none of the results derived below is qualitatively affected by the type of competition being based on quantity rather than on price. The only exception is given by relationship between strength of incentives and intensity of competition; below we show that this relationship can be U-shaped, while it is unambiguously negative under Bertrand competition (see also Schmutzler, 2010).

Second, in the model, applied and basic research efforts enter linearly and separately into the production cost function. An alternative specification could include an interaction term between the two efforts, capturing complementarities between applied and basic research. Notice, however, that the current formulation already induces complementarity between the two types of research, since an increase in the level of one type of research increases the marginal return from performing the other type. The intuition for this goes as follows. Consider an exogenous increase in one of two efforts. This brings about a reduction in costs, which leads a firm to expand its size; in turn, the incentive to invest in the other type of effort increases since larger firms have stronger incentives in investing in cost-reducing innovation. If an interaction term is included in the production cost function, this would add an additional source of complementarity between applied and basic research (of a purely knowledge nature in this case, rather than a strategic one) and would simply expand the area of the parameter space in which variations in the parameters lead to the same direction 
of change in the piece rates. ${ }^{6}$

Third, and related to the previous point, also the cost of effort is separable. We opted for this formulation (as in other studies, such as Baker, 2002; and Gibbons, 2005a) in order to focus our attention on other determinants of scientific efforts (and their co-movement), in a framework where complementarities in types of research emerge from the interaction of firms in the product market. Also, simple and tractable formulations of the cost function allowing for interactions between efforts would produce results, in the context of our model, that do not seem particularly interesting nor realistic. For instance, consider the cost function $\gamma\left(\frac{e^{A}+e^{B}}{2}\right)^{2}$. If the contract offered to the scientists is linear, then the scientists would invest only in applied research if $\alpha^{A}>\alpha^{B}+\rho$, or in basic research otherwise; this would go against the evidence of firms investing in both types of research.

Fourth, we consider scientific effort as valuable in that it reduces production costs. We are therefore considering process innovations. However, the model can accommodate some types of product innovation as well (Vives, 2008). In particular, quality improvements in existing products can be modeled as an increase in consumers' willingness to pay for a product. Suppose that the scientists' effort, instead of reducing the baseline marginal cost $c$, increases the maximum willingness to pay $A$ in the demand function (equation (1)). Thus the firms' profit functions, and therefore their optimal contract decisions, will be unaffected as compared to the case developed here. ${ }^{7}$

Fifth, notice that knowledge spillovers, in the model, do not occur directly through publications or patents. It is implicitly assumed that the firms can effectively protect their proprietary knowledge, even when it is made public through either patents or publications. The assumption is quite obvious as long as patents are concerned, but it is also a plausible choice with respect to publications: firms typically delay publications of their scientists (and of independent scientific partners) until confidential information and intellectual property are secured (Blumenthal et al., 1986). Knowledge spillovers, however, can still occur through more informal and less verifiable channels. These channels include interpersonal relations and conversations among scientists from different organizations, as well as labor mobility. Plausibly, it is harder for a firm to control these flows of information. ${ }^{8}$ The model captures the difference between "appropriable" and "pure" knowledge spillovers by having the wage schedule depend on codified measures, e.g. publications (see expression (6) above), while knowledge spillovers occur directly through the unverifiable (by a third party) effort (as in the cost function (3)). The model also considers the fact that knowledge is more likely to be transmitted if it is more basic, thus less firm-specific than knowledge from

\footnotetext{
${ }^{6} \mathrm{~A}$ formal analysis of the effect of knowledge complementarities between applied and basic research is available upon request.

${ }^{7}$ In contrast, our model cannot accommodate for innovations consisting in both the introduction of new products and changes in the degree of product differentiation (and then, the intensity of competition.)

${ }^{8}$ If spillovers occurred directly through publications and/or patents, it would be interesting to study the firms's disclosure strategies by making the parameter $\beta$ endogenous. Mukherjee and Stern (2009), for example, consider the trade-off between secrecy and disclosure, and find that different regimes ("Open Science", "Secrecy" or cycles between the two) can be sustained as equilibria. Gans et al. (2010) assume that knowledge can be disclosed through patents and/or publications.
} 
applied research, and that the transmission of knowledge is imperfect. The former fact is captured by having knowledge spillovers occur only through effort in basic research; the imperfection in the transmission of knowledge is captured by having $\beta$, i.e. the share of a scientist's basic research effort that benefits a rival firm, within the unit interval. In fact, one could argue that, especially in some disciplines, such as engineering or computer science, most publishable research is applied and not basic. Therefore, also this type of research can generate spillovers and also enhance a scientist's reputation among peers. An alternative terminology would be to define $e^{A}$ as effort in "proprietary" research, and $e^{B}$ as effort in "open" research. Throughout the paper we will keep with the applied/basic terminology, but the alternative dichotomy can also be employed.

Related to the previous point, notice that the intensity of knowledge spillovers between companies is not be related to the intensity of product market competition. Even when product markets are separated, for instance, the relevant knowledge that allows innovation for one product can be relevant for the other product. Furthermore, while different geographical areas may be isolated in terms of final product competition (e.g. by regulation), researchers can still communicate and diffuse their knowledge through other channels. Conversely, firms may operate in similar markets and compete fiercely, but use different technologies, so that knowledge spillovers are low. ${ }^{9}$

Finally, we are making two other assumptions on the scientists's preferences, in addition to the form of the effort cost function. One assumption is that they are risk-neutral. This makes our setting equivalent to one where efforts were observable; consequently, the principal-agent framework could be considered as redundant. However, we preferred to maintain this representation for a number of reasons. First, some assumptions, e.g. the notion of scientists' "taste for science," are more naturally understood in this context. Second, the empirical literature we refer throughout the paper adopts a principal-agent theoretical framework. Finally, we have indeed analyzed a version of the model with risk aversion (this analysis is available upon request). ${ }^{10}$ Although the analysis is algebraically more cumbersome, our key results are qualitatively the same as in the risk-neutral case. More generally, the agent's risk attitude is not at the core of our analysis. While risk aversion has been traditionally a basic element of principal-agent models, Gibbons (2005b) suggests examples of recent contributions in agency theory where other aspects (such as multi-task) provide key insights even with risk neutrality.

The second assumption about the scientists' preferences is that their utility depends both on

\footnotetext{
${ }^{9}$ As an example of research aimed at a given market segment that is relevant for different segments, consider the research for cardiovascular-related diseases that turned out to be useful for the correction of erectile dysfunctions (Kling, 1998; Pietsch, 2006). Similarly, airplane producers and automakers, or computer and cellphone manufacturers, use similar technologies but do not operate in the same markets (Bloom et al., 2008). Alcacer and Zhao (2007) and Bloom et al. (2008), moreover, document that firms that compete with each other may employ different technologies.

${ }^{10}$ In the extension, the change with respect to the model presented here is in the scientists' utility function, modeled as a negative exponential utility with constant coefficient of absolute risk aversion $r$ : $U_{i}=$ $-e^{-r\left[w_{i}+\rho e_{i}^{B}-\left(\gamma_{A} \frac{\left(e_{i}^{A}\right)^{2}}{2}+\gamma_{B} \frac{\left(e_{i}^{B}\right)^{2}}{2}\right)\right]}$. extension we are also allowing for the productivity of effort in basic and applied research to differ, by having cost parameters $\gamma^{A}$ and $\gamma^{B}$.
} 
monetary returns and on a taste for science, and in particular basic research. This assumption is in line with a vast literature on the direct benefits (psychological and social) that scientists derive from performing activities that advance knowledge and are recognized in the community of peers - features that characterize basic, open science (Dasgupta and David, 1994; Merton, 1973; Roach and Sauermann, 2010). In other words, scientists have both extrinsic and intrinsic motivations. A recurrent theme in the literature on intrinsic and extrinsic motivation (Frey, 1997) is related to the "crowding out" effect, i.e. the idea that extrinsic motivation (in our case, high-powered incentives) would undermine intrinsic motivation (in our case, the taste for science). We rule out this possibility, by assuming that the monetary and non-monetary component of the utility function are independent - as we will see below, despite the "technical" independence, explicit and implicit rewards are complementary in our model. Bénabou and Tirole (2003) develop a model where "crowding out" effects are likely to occur when a principal has private information about the task or the agent's characteristics, and the agent infers such information from the principal's behavior. These conditions do not seem to fit our case.

\subsection{Deriving the optimal incentive scheme}

The model is solved by backward induction, starting from the quantity choices in the product market. The focus is on firm $i$. The results for firm $j$ are easily obtained.

\subsubsection{Market competition}

Firm $i$ maximizes its profit by solving the following problem:

$$
\underset{q_{i}}{\operatorname{Max}} \Pi_{i}=\left(p_{i}-c_{i}\right) q_{i}=\left(A-q_{i}-\lambda q_{j}-c_{i}\right) q_{i} .
$$

Considering that the problem for firm $j$ is symmetric, and solving for the (necessary and sufficient) first order condition for $q_{i}$ gives the equilibrium quantity and profits:

$$
\begin{aligned}
q_{i}^{*} & =\frac{A-\frac{\left(2 c_{i}-\lambda c_{j}\right)}{2-\lambda}}{\lambda+2} ; \\
\Pi_{i}^{*} & =\left[q_{i}^{*}\right]^{2}=\left[\frac{A-\frac{\left(2 c_{i}-\lambda c_{j}\right)}{2-\lambda}}{\lambda+2}\right]^{2} .
\end{aligned}
$$

\subsubsection{The scientist's effort choice}

The effort choices of scientist $i$ are straightforward to obtain, given the incentive scheme and the taste for science. They are increasing in the piece rates, and effort in basic science is also increasing in the degree of taste for science. Both efforts are decreasing in the difficulty of the tasks as represented by the cost parameter $\gamma$ : 


$$
\begin{aligned}
e_{i}^{A} & =\frac{\alpha_{i}^{A}}{\gamma} \\
e_{i}^{B} & =\frac{\rho+\alpha_{i}^{B}}{\gamma} .
\end{aligned}
$$

\subsubsection{The principal's incentive provision problem}

Following Holmstrom and Milgrom (1987), the principal's choice of the optimal contract is obtained from maximizing the expected total surplus $T S$, subject to the incentive compatibility constraints, given by the scientist's optimal effort choices. This defines a constrained maximization problem that can be written as:

$$
\begin{aligned}
\underset{\alpha_{i}^{0}, \alpha_{i}^{A}, \alpha_{i}^{B}}{\operatorname{Max}} E\left(T S_{i}\right)= & \Pi_{i}+\rho e_{i}^{B}-\gamma\left[\frac{\left(e_{i}^{A}\right)^{2}}{2}+\frac{\left(e_{i}^{B}\right)^{2}}{2}\right] \\
& \text { s.t. }(11) \text { and }(12) .
\end{aligned}
$$

This lead to our first proposition that derives the incentive piece rates $\alpha_{E}^{A}$ and $\alpha_{E}^{B}$ (the subscript $E$ stands for "Equilibrium"), symmetric for the two firms.

Proposition 2.1 The firms determine the incentive piece rates $\alpha_{E}^{A}$ and $\alpha_{E}^{B}$ as follows:

$$
\begin{gathered}
\alpha_{E}^{A}=\frac{4[\gamma(A-c)+\rho(1+\beta)]}{\gamma k-4-2(1+\beta)(2-\beta \lambda)} ; \\
\alpha_{E}^{B}=\frac{2[\gamma(A-c)+\rho(1+\beta)](2-\beta \lambda)}{\gamma k-4-2(1+\beta)(2-\beta \lambda)},
\end{gathered}
$$

where $k \equiv(\lambda+2)^{2}(2-\lambda)$. The fixed component of wage $\alpha_{E}^{0}$ is set so as the scientists obtain their reservation utility $\bar{u}$.

From expressions (14) and (15), a series of comparative statics can be performed. These experiments are the subject of the following Section, where we study the impact of competition, knowledge spillovers and taste for science on the strength, direction and complementarity of incentive mechanisms.

\section{Implications: the impact of competition, knowledge spillovers, and non-monetary motives on the optimal incentive contract}

The implications of the model are analyzed in two parts. In the first part, we study how knowledge spillovers and the intensity of competition affect the relative and absolute strength of incentives, and we determine the competitive and knowledge-appropriability conditions under which the two 
incentive rates are complementary. In the second part, we focus on how the presence of nonmonetary motives for basic research affects the definition of the incentive contract. The propositions presented below are preceded by an informal description of, and the intuitions behind the results. Each of the two subsections also include a discussion of how the model helps to interpret the existing empirical evidence on the provision of incentives to corporate scientists.

\subsection{Competition, Spillovers, and Incentives}

\subsubsection{The relative strength of incentives}

The higher the competitive pressure on the product market and the higher the ease with which knowledge spills over to competitors, the stronger the incentives to perform applied research in comparison to basic research. Since spillovers occur only through basic research, firms find it relatively more profitable to reward those activities that, while reducing costs, do not produce externalities (thus benefiting competitors). When $\beta=0$ or $\lambda=0$, note that neither the intensity of competition nor the ease with which knowledge spills over to competitors has an effect on the relative strength of incentives.

Proposition 3.1 The ratio between the two piece rates, $\frac{\alpha_{E}^{A}}{\alpha_{E}^{B}}$, is increasing in $\lambda$ and $\beta$.

\subsubsection{Knowledge spillovers and the shape of the optimal contract}

In general, the effect of knowledge spillovers from basic research (as measured by the parameter $\beta$ ) on the absolute strength of incentives is ambiguous. On the one hand, there is a positive effect of incoming spillovers. As previously noticed, larger firms have higher incentives to invest in costreducing $R \& D$. Consequently, a decrease in unit costs due to larger incoming spillovers leads firms to provide stronger incentives both for basic and applied research. On the other hand, giving strong incentives to scientists benefits the competing firm by reducing its costs through outgoing spillovers, thus increasing the competitor's size and profits at the detriment of the firm originating the spillovers. This has a negative effect on the provision of incentives for basic research as well as for applied research, due to the firm's smaller size. The overall impact of the degree of knowledge spillovers turns out to depend crucially on the intensity of product market competition.

When the intensity of competition $\lambda$ is sufficiently low, the positive effect of outgoing spillovers prevails, both $\alpha_{E}^{A}$ and $\alpha_{E}^{B}$ are increasing in $\beta$, and the negative impact of knowledge spillovers vanishes. Each firm is reinforced by the spillovers deriving from the other firm; this reinforcement, however, does not hamper the profitability of the originating firms since there is limited direct interaction in the final market. As a consequence, firms exploit the cost-reducing impact of knowledge spillovers in full, by reinforcing the incentives to their scientists. At the other extreme, when both $\beta$ and $\lambda$ are high, $\frac{\partial \alpha_{E}^{A}}{\partial \beta}$ and $\frac{\partial \alpha_{E}^{B}}{\partial \beta}$ are both negative. Low investments in basic research lead firms to operate at higher costs, which is detrimental to the incentives for cost-reduction through applied research efforts. Finally, in the intermediate case, there is a "substitution effect" that favors 
applied research against basic research following from Proposition 3.1 above: firms provide higher incentives for applied research, which does not generate spillovers to competitors, while reducing the incentives for basic research for which spillovers to competitors are present. This leads to $\frac{\partial \alpha_{E}^{A}}{\partial \beta}>0$ and $\frac{\partial \alpha_{E}^{B}}{\partial \beta}<0$. The previous considerations are formalized in the following propositions and corollaries:

Proposition $3.2 \alpha_{E}^{A}$ is increasing in $\beta$ if $\lambda<\lambda_{A}^{*}$, where $\lambda_{A}^{*}$ is the unique solution to $\frac{\partial \alpha_{E}^{A}}{\partial \beta}=0$, and $\lambda_{A}^{*}$ is decreasing in $\beta$.

Corollary 3.2.1 $\alpha_{E}^{A}$ is always increasing in $\beta$ if $\lambda<\frac{2}{3}$ or $\beta<\frac{1}{2}$.

Proposition $3.3 \alpha_{E}^{B}$ is increasing in $\beta$ if $\lambda<\lambda_{B}^{*}$, where $\lambda_{B}^{*}$ is the unique solution to $\frac{\partial \alpha_{E}^{B}}{\partial \beta}=0$, and $\lambda_{B}^{*}$ is decreasing in $\beta$. Furthermore, $\lambda_{B}^{*} \leq \lambda_{A}^{*}$.

Corollary 3.3.1 $\alpha_{E}^{B}$ is always decreasing in $\beta$ if $\lambda>\frac{2}{3}$ or $\beta>\frac{1}{2}$.

Figure 2 provides a graphical example of these results, by showing the relevant regions for $\frac{\partial \alpha_{E}^{A}}{\partial \beta}$ and $\frac{\partial \alpha_{E}^{B}}{\partial \beta}$ in the $(\lambda, \beta)$ space, while the other parameters are chosen in order to guarantee that the second order conditions are satisfied for all values of $\beta$ and $\lambda$.

\subsubsection{Competition and the shape of the optimal contract}

We now investigate the relationship between the strength of incentives provided to scientists and the intensity of competition as measured by $\lambda$. This analysis evokes the issue of the relationship between the intensity of competition and the incentives to innovate, which has been long debated in economics since Schumpeter (1943) and Arrow (1962). Again, the interaction between degree of knowledge spillovers and competition comes to play a key role.

There are two effects relating $\lambda$ and the incentives to research. If $\lambda$ is small, so that competition is limited, firms are larger, ceteris paribus. This provides high incentives for cost-reduction (such an effect can be seen in the denominator of (9), page 10). If $\lambda$ is large, a firm's profits are more sensitive to its own costs and the other firm's cost (as can be seen from expression (9) representing the optimal quantities produced). This tends to reduce the incentives to innovation, especially when knowledge spillovers are high, since the marginal reduction of the other firm's cost is higher in this case.

The net effect of these contrasting forces is as follows. The coefficients $\alpha_{E}^{A}$ and $\alpha_{E}^{B}$ are decreasing in $\lambda$ if $\lambda<\frac{2}{3}$, irrespective of $\beta$. If $\lambda>\frac{2}{3}$, there are three different regions. If $\beta$ is sufficiently low, then both $\alpha_{E}^{A}$ and $\alpha_{E}^{B}$ are increasing in $\lambda$. This means that in this case the relationship between the intensity of competition and the power of incentives to the scientists is U-shaped, i.e. $\alpha_{E}^{A}$ and $\alpha_{E}^{B}$ are minimal for an intermediate level of $\lambda .{ }^{11}$ For intermediate values of $\beta$, an increase in $\lambda$ has

\footnotetext{
${ }^{11}$ This result extends Sacco and Schmutzler (2009) and Belleflamme and Vergari (2006). Sacco and Schmutzler (2009) consider the same duopoly model as we do, but with one-dimensional effort. In Belleflamme and Vergari (2006), only one firm has access to innovation. Furthermore, both models assume that innovations are always perfectly appropriable and do not consider the effects of the presence of knowledge spillovers.
} 
a positive effect on $\alpha_{E}^{A}$, but a negative effect on $\alpha_{E}^{B}$. Again, a substitution effect is present since higher $\lambda$ particularly reinforces the negative effect of spillovers on $\alpha_{E}^{B}$ when $\beta$ is high. Finally, for high values of $\beta, \alpha_{E}^{A}$ and $\alpha_{E}^{B}$ are both decreasing in $\lambda$. In this case, lower investment in basic research also leads to a reduction in applied research. ${ }^{12}$

Proposition $3.4 \alpha_{E}^{A}$ is increasing in $\lambda$ if $\lambda>\lambda_{A}^{* *}$, where $\lambda_{A}^{* *}$ is the unique solution to $\frac{\partial \alpha_{E}^{A}}{\partial \lambda}=0$, and is increasing in $\beta$. If the critical value $\lambda_{A}^{* *}$ is greater than 1 , then $\alpha_{E}^{A}$ is always decreasing in $\lambda$.

Proposition $3.5 \alpha_{E}^{B}$ is always increasing in $\lambda$ if $\lambda>\lambda_{B}^{* *}$, where $\lambda_{B}^{* *}$ is the unique solution to $\frac{\partial \alpha_{E}^{B}}{\partial \lambda}=0$, and is increasing in $\beta$. Furthermore, $\lambda_{B}^{* *} \leq \lambda_{A}^{* *}$.

Figure 3 shows the relevant regions for $\frac{\partial \alpha_{E}^{A}}{\partial \lambda}$ and $\frac{\partial \alpha_{E}^{B}}{\partial \beta}$ in the $(\lambda, \beta)$ space, using for the other parameters the same numerical values as in Figure 2 above.

\subsubsection{Are the incentive instruments complementary?}

Ultimately, R\&D managers are interested in the design of a whole incentive system for scientists, and not only in the choice of each single effort-enhancing measure (Cockburn et al., 1999; Holmstrom and Milgrom, 1994). Our model also holds predictions on how the piece rates co-move, and in particular on their complementarity. The variables $\alpha_{i}^{A}$ and $\alpha_{i}^{B}$ are said to be complementary to a given parameter when an increase in the parameter leads to an increase in the marginal return from $\alpha_{i}^{A}$ and $\alpha_{i}^{B}$, and, simultaneously, the increase in the level of one of the piece rates increases the marginal return from the other (Holmstrom and Milgrom, 1994). The latter condition is always satisfied, because $\frac{\partial^{2} E(T S)}{\partial \alpha_{i}^{A} \alpha_{i}^{B}}=\frac{4(2-\beta \lambda)}{\gamma^{2}(2-\lambda)^{2}(2+\lambda)^{2}}>0$. The analysis lead to the following findings.

Consider, first, product market competition. The incentive instruments $\alpha_{i}^{A}$ and $\alpha_{i}^{B}$ are complementary to $\lambda$ when product market competition is sufficiently intense and spillovers are not too high. When $\lambda$ is high and $\beta$ is low, the marginal impact on profits of each type of research is high, and the effects reinforce each other. Complementarity between the incentive instrument and the level of knowledge spillovers holds also in the opposite case, i.e. when the level of competition is low. The following two propositions formalize these results:

Proposition $3.6 \alpha_{i}^{A}$ and $\alpha_{i}^{B}$ are complementary in $\lambda$ if $\lambda>\underline{\lambda}(\beta)$, with $\underline{\lambda}(\beta) \geq \frac{2}{3}$ and $\frac{d \underline{\lambda}(\beta)}{d \beta}>0$.

Proposition $3.7 \alpha_{i}^{A}$ and $\alpha_{i}^{B}$ are complementary in $\beta$ if $\lambda \rightarrow 0$.

\subsubsection{Discussion}

The main insight from this first set of results is not only that such characteristics as product market competition and knowledge spillovers matter in the determination of incentives to scientists, but also

\footnotetext{
${ }^{12}$ These results (and their intuitions) are similar to those derived by Schmutzler (2010). His model (in which cost-reducing investments are unidimensional) is more general than the one presented here - thus lending some support to the robustness of our findings. The results however depend on a specific assumption that we do not make. Schmutzler's analysis also does not include the agency problem that we consider in our model.
} 
that they interact. In addition to this theoretical insight, a major implication for empirical analysis is that the structure of the industry and the IP regimes need to be controlled for when assessing the determinants of scientists' pays and incentive structures. Cockburn et al. (1999), for example, find that incentives for basic and applied research are complementary in the pharmaceutical industry: when firms commit to high-powered incentives to obtain recognition in the scientific community, they also offer higher-powered rewards for applied activities. The authors use data at the level of research programs; arguably, different research programs refer to different final product markets, thus our model suggests an extension of the work of Cockburn et al., consisting of the estimate of the relation between basic and applied research incentives separately for each submarket, in order to account for potentially different competitive and knowledge-appropriability conditions.

In a study of the wage determination of software developers, Andersson et al. (2009) find that wages are more responsive to performance in more "risky" industry segments, where riskiness is measured in terms of the 90/50 ratio of product line sales per worker. The authors offer a sorting explanation for their results. Firms in highly risky environments benefit more from having star workers. In order to attract them, firms offer a better pay, both in terms of fixed and performance related-wage. Our results point to additional (though not necessarily mutually exclusive) explanations. Consider, for example, the video game software developing/publishing segment, indicated by Andersson et al. as the riskiest in their sample. Williams (2002), moreover, reports that this segment has experienced increased concentration over the 1990s, up to a four-firm concentration ratios greater than $50 \%$ in the early 2000s. The IT-software online journal SoftwareMag.com publishes a list of the biggest software companies. Among the 100 biggest companies of this survey, only two declare "Database" as their primary product line; eight indicate software for financial applications, and nine indicate infrastructure/networking software. Among these three segments, Andersson et al. indicate "networking" as the riskiest, and "database" as the least risky. Therefore, some of the riskiest segments of the industries are also those where firms are of larger size, which in our model corresponds to lower competitive pressure. In addition, intellectual property protection in software is relatively weak, and knowledge spillovers are pervasive. ${ }^{13}$ If higher riskiness happens to be associated with the presence of larger firms, then our model predicts that companies offer higher powered incentives in less competitive product lines (where firms are larger).

\footnotetext{
${ }^{13}$ Graham and Mowery (2003) report that, until the early 1990s, the major form of IP protection for software was through copyright. A series of court rulings, however, have reduced the power of copyright in preventing imitation by rivals. In more recent years, companies have increasingly patented their software inventions. Since software patents have been used only recently, the absence of a prior art has made it difficult for examiners to assess the appropriateness of a patent application. Besides, patent systems around the world, in a typically global industry, have shown differing degrees of severity in accepting applications. It is reasonable to conclude that patents have only a limited role in the protection of software. Notice, also, that the majority of software patents are held by non-software companies. Finally, job hopping is widespread in the software industry, thus allowing ideas and possibly secrets to move from one company to another, together with people who carry these ideas (Fallick et al., 2006; Freedman, 2006).
} 


\subsection{Monetary wage and non-pecuniary benefits: a trade-off?}

We now move to the analysis of the relationship between the non-monetary drivers of scientific effort, such as scientific curiosity or the desire to excel in the community of peers, and a firm's decision of the type of incentive contract to offer to scientists. In the model, the non-monetary motives are expressed by the parameter $\rho$ in the scientists' utility function. As a direct effect, an increase in the researcher's taste for science makes effort in basic research more attractive; in turn, through its positive effect on the firm's size, this leads the firm to increase the power of the incentives both for basic and applied research. In other words, the firm prefers to reinforce the non-monetary incentives through the wage schedule. This mechanism leads to the following proposition:

Proposition 3.8 Both $\alpha_{E}^{A}$ and $\alpha_{E}^{B}$ are increasing in $\rho ; \alpha_{i}^{A}, \alpha_{i}^{B}$ and $\rho$ are complementary.

The presence of a taste for science $\rho$ has also implications for determining the fixed component of wage, $\alpha^{0}$. In the standard case, $\alpha^{0}$ is simply determined by the participation constraint, which is binding in equilibrium. In our framework, it is interesting to study how the fixed wage varies with $\rho$. The effect is a-priori ambiguous. Higher $\rho$ implies that the scientists obtain a higher benefit from basic research. At the same time, as from Proposition 3.8, the scientists exert higher effort in both applied and basic research, for which they must be compensated. It turns out that the first effect prevails, thus $\alpha_{E}^{0}$ (the fixed wage in equilibrium) is always decreasing in $\rho$. This result is summarized in the next proposition:

Proposition $3.9 \alpha_{E}^{0}$ is decreasing in $\rho$.

Last, we look at the relationship between the overall expected wage $\alpha_{E}^{0}+\alpha_{E}^{A} E\left(X^{A}\right)+\alpha_{E}^{B} E\left(X^{B}\right)$ and the degree of non-monetary benefits. We show that for low levels of $\rho$, the expected wage is increasing in $\rho$, i.e. the effect on the piece rates prevails. For high $\rho$, examples both for the case in which the expected wage is increasing and for the case in which it is decreasing in $\rho$ can be found.

Proposition 3.10 The expected wage $\alpha_{E}^{0}+\alpha_{E}^{A} E\left(x_{A}\right)+\alpha_{E}^{B} E\left(x_{A}\right)$ is increasing in $\rho$ when $\rho$ is small. $\alpha_{E}^{0}+\alpha_{E}^{A} E\left(x_{A}\right)+\alpha_{E}^{B} E\left(x_{A}\right)$ may be increasing or decreasing in $\rho$ when $\rho$ is high.

\subsubsection{Discussion}

This second set of results, also, offer insights to empirical research. Again, we use some existing empirical studies to show the relevance of our findings. In a detailed study of the organization of research in a major biotechnology company, Liu and Stuart (2010) find that the contingent component of scientists' pay is positively related to the their publication performance. The positive association is particularly strong for Ph.D. scientists, who, plausibly, are those with a higher taste for science. Our model thus offers an explanation for Liu and Stuart's findings. Stern (2004) 
investigates whether the $R \& D$ orientation of firms leads scientists to accept lower wages. He finds that firms that allow their researchers to publish their findings, or even reward scientists for their publications, offer lower monetary wages. Stern concludes that researchers show a taste for science. The model in this paper is in line with this claim as it includes, through the parameter $\rho$, nonpecuniary benefits for company scientists when they engage in basic science. We show a negative relation between the taste for science and the fixed component of wage, but a positive relationship with piece rates. Furthermore, we show that the overall expected wage is increasing in $\rho$ when $\rho$ is not too high. Using Stern's terminology, we can claim that a "productivity effect" acts at the level of the performance-based component of wage, while a "preference effect," i.e. the willingness of a science-oriented researcher to give up money in exchange for science, acts on the fixed salary (which is what Stern is able to observe).

In addition to providing novel theoretical insights and to interpreting empirical findings, the model also has a number of implications for managers and entrepreneurs as well as for policymakers. These further insights are discussed in the following Section.

\section{Managerial and policy implications: R\&D organization and be- yond}

Providing incentives to corporate scientists is a complex problem that requires to consider the nature of the knowledge that scientists are expected to generate, the monetary and intrinsic motivations of researchers, and the competitive conditions in the markets where a firm operates. If a company is positioned so as to enjoy market power, cost-reducing efforts by its scientists are likely to have a sizeable impact on the level of profits. When competition is more intense, cost reduction might instead be crucial for survival, thus again leading firms to provide stronger incentives to scientists for process innovations. The latter case, however, depends also on the degree to which the knowledge produced by a firms's scientists spills over to rivals. If these spillovers are high, then incentivizing scientists too strongly results in offering an advantage to rivals. In an environment where knowledge flows easily, managers and entrepreneurs should be aware that the organizational responses to market competition may be different than in a world of more "private" knowledge. Conversely, the level of knowledge appropriability has a different impact in highly and weakly competitive markets. In the former type of markets, as said, low appropriability may offer an advantage to competitors which, in turn, backfires on the focal company. When competition on the product market is low, by contrast, each firm is reinforced by the spillovers deriving from the other firm; this reinforcement, however, does not affect the profitability of the originating firms, since there is limited direct interaction in the final market. Finally, scientists who are more eager to maintain

their links to the scientific community even when employed by a firm, and are allowed by a firm to do so, are not necessarily "cheap," since it may be optimal for a firm to provide them with more powerful incentives and higher expected wages. 
The above considerations are useful also to analyze how organizations motivate other types of workers. Just as in the case of firms dealing with researchers, such issues as competitive pressure, leakage of relevant information, multidimensional effort and multiple motivations are going to be of relevance for other professions within companies, and for other organizations. Examples include such industries as health care and advertising (Gaynor et al., 2005; Von Nordenflycht, 2007), and such organizations as universities, hospitals, and the military.

A further application of the model is in the policy debate, with particular reference to the two major instruments in industrial policy: competition and intellectual property (IP) policy. Our analysis implies that IP protection rules should be determined in relation to the level of competition of each industry and that, in particular, antitrust legislation and IP protection are complementary instruments. When companies face low competition on the final market, they have "nothing to fear" from low knowledge appropriability; instead, they find it even more profitable to motivate the performance of basic (open) research by their scientists. Conversely, in industries where IP protection is very strong, competition on the product market should be particularly favored. Ganslandt (2007) shows that, in fact, there is a strong positive correlation, across countries, between strength of IP protection and effectiveness of antitrust regulations.

\section{$5 \quad$ Summary and directions for future research}

The model of incentive provision to company scientists developed in this paper is based on four key characteristics of research activities. First, scientists engage in multiple, different activities when performing research, e.g. in (proprietary) applied and (open) basic research. Second, the knowledge produced through research activities is not perfectly appropriable. Third, scientists are responsive both to monetary incentives and to non-material motives, such as their reputation in the community of peers. Fourth, the provision of incentives depends on the conditions a firm faces in the product market, such as the intensity of competition.

We show that the strength of incentives for applied and basic research depends on the interaction of intensity of competition and degree of knowledge spillovers. Greater knowledge spillovers positively affect the provision of incentives only when competition is low, whereas in more competitive environments, the impact of higher knowledge spillovers on the incentive scheme is ambiguous. The relationship between the intensity of competition and the power of incentives to scientists is in general U-shaped, with the exact shape and slopes, again, crucially depending on the intensity of spillovers. An implication of these findings is that incentives for basic and applied research are complementary only if either competition or knowledge spillovers are low. We also show that the incentives for both applied and basic research increase with the non-pecuniary benefits that scientists obtain from basic research, while a trade-off between monetary pay and non-monetary rewards can occur at the level of the fixed salary.

Empirical studies of the determinants of incentives to scientists need to account for such environ- 
mental conditions as the degree of product market competition and of appropriability of knowledge, and need to analyze separately different components of wages, e.g. fixed and contingent pays, since they might respond differently to certain changes. Similarly, firms need to look at their position in the product market, and at the knowledge appropriability conditions for different types of activities, when designing their internal R\&D organization. Managers should also account for the non-monetary motivations of scientists. The model in this paper, finally, implies that policymakers should see antitrust and IP legislation as related (and complementary) measures.

The analysis in this paper can be extended in a number of directions. A richer setup would consider firms differing in their focus on, or their efficiency in, different types of research, as well as scientists differing in their abilities and motivations. A further related extension would be to model the interaction between the incentive provision problem and the labor market for scientists. The incentive schemes would be devised so as to equalize returns across firms, and if firms and scientists are heterogeneous, matching dynamics would also be relevant (Besley and Ghatak, 2005). Furthermore, scientists also have the opportunity to work in academia, and presumably the value of this "outside option" is affected by their taste for science (Roach and Sauermann, 2010). The model, finally, focuses on competition among firms. Further developments would also explore how the incentive provision problem changes when firms cooperate in R\&D. ${ }^{14}$ In turn, the comparison between competitive and cooperative outcomes is a natural step in the analysis of the welfare consequences in addition to some of the conjectures made in the paper.

\section{References}

[1] Alcacer, J. and Zhao, M., 2007: "Global Competitors and Next-Door Neighbors: Competition and Geographic Co-location in the Semiconductor Industry," working paper.

[2] Andersson, F., Freedman, M., Haltiwanger, J.C., Lane, J. and Shaw, K.L., 2009: "Reaching for the Stars: Who Pays for Talent in Innovative Industries?," Economic Journal, 119, F308-F332.

[3] Arrow, K., 1962: "Economic Welfare and the Allocation of Resources for Invention," in The Rate and Direction of Inventive Activity: Economic and Social Factors, National Bureau Of Economic Research, Princeton University Press, Princeton (NJ), 609-619.

[4] Baggs, J. and de Bettignies, J., 2007: "Product Market Competition and Agency Costs," Journal of Industrial Economics, 55, 2, 289-323.

[5] Baker, G., 2002: "Distortion and Risk in Optimal Incentive Contracts," Journal of Human Resources, $37,4,728-751$.

\footnotetext{
${ }^{14}$ See, among others, D'Aspremont and Jacquemin (1988), Lin and Saggi (2002), and Rosenkranz (2003).
} 
[6] Banal-Estañol, A. and Macho-Stadler, I., 2010: "Commercial Incentives in R\&D: Research vs. Development," Journal of Economics and Management Strategy, 19, 1, 185-221.

[7] Belleflamme, P. and Vergari, C., 2006: "Incentives to Innovate in Oligopolies," CORE Discussion Paper 14.

[8] Benabou, R. and Tirole, J, 2003: "Intrinsic and Extrinsic Motivation," Review of Economic Studies, $70,489-520$.

[9] Besley, T. and Ghatak, M., 2005: "Competition and Incentives with Motivated Agents," American Economic Review, 95, 3, 616-636.

[10] Bloom, N., Schankermann, M.A. and Van Reenen, J., 2008: "Identifying Technology Spillovers and Product Market Rivalry," working paper.

[11] Blumenthal, D., Gluck, M., Seashore Louis, K. and Wise, D., 1986: "Industrial Support for University Research in Biotechnology," Science, 231, 4735, 242-246.

[12] Cockburn, I., Henderson, R. and Stern, S., 1999: "Balancing Incentives: The Tension Between Basic and Applied Research," NBER Working Paper 6882.

[13] D'Aspremont, C. and Jacquemin, A., 1988: "Cooperative and Noncooperative R \& D in Duopoly with Spillovers," American Economic Review, 78, 5, 1133-1137.

[14] Dasgupta, P. and David, P., 1994: "Towards A New Economics of Science," Research Policy, 23, 487521.

[15] Dennis, M.A., 1987: "Accounting for Research: New Histories of Corporate Laboratories and the Social History of American Science," Social Studies of Science, 17, 3, 479-518.

[16] De Bondt, R., 1997: "Spillovers and Innovative Activities," International Journal of Industrial Organization, 15, 1-28.

[17] Fallick, B., Fleischman, C.A. and Rebitzer, J.B., 2006: "Job-Hopping in Silicon Valley: Some Evidence Concerning the Microfoundations of a High-Technology Cluster," Review of Economics and Statistics, $88,3,472-481$.

[18] Freedman, M., 2006: "Job Hopping, Earnings Dynamics, and Industrial Agglomeration," working paper.

[19] Frey, B., 1997: Not Just For the Money: An Economic Theory of Personal Motivation, Edward Elgar Publishing Limited, Cheltenham.

[20] Gans, J.S., Murray, F.E. and Stern, S., 2010: "Contracting over the Disclosure of Scientific Knowledge: Intellectual Property Protection and Academic Publication," working paper. 
[21] Ganslandt, M., 2007: "Intellectual Property Rights and Competition Policy," in Beladi H. and Choi, E.K. (eds.), Frontiers of Economics and Globalization, 2, 233-261.

[22] Garnier, J.P., 2008: "Rebuilding the R\&D Engine in Big Pharma," Harvard Business Review, May issue, 69-76.

[23] Gaynor, M., Rebitzer, J.B. and Taylor, L.J., 2005: "Physician Incentives in Health Maintenance Organizations," Journal of Political Economy, 112, 4, 915-931.

[24] Gibbons, R., 2005a: "Four formal(izable) theories of the firm?," Journal of Economic Behavior and Organization, 58, 200-245.

[25] Gibbons, R., 2005b: "Incentives Between Firms (and Within)," Management Science, 51, 1, 2-17.

[26] Gittelman, M. and Kogut, B., 2003: "Does Good Science Lead to Valuable Knowledge? Biotechnology Firms and the Evolutionary Logic of Citation Patterns," Management Science, 49, 4, 366-382.

[27] Graham, S. and Mowery, D., 2003: "Intellectual Property Protection in the Software Industry," in Cohen, W. and Merrill, S. (eds.), Patents in the Knowledge-based Economy: Proceedings of the Science, Technology and Economic Policy Board, National Academies Press.

[28] Hart, O., 1983: "The Market Mechanism as an Incentive Scheme," Bell Journal of Economics, 14, $366-82$.

[29] Henderson, R. and Cockburn, I., 1994: "Measuring Competence? Exploring Firm Effects in Pharmaceutical Research," Strategic Management Journal, 15, 63-84.

[30] Henderson, R. and Mitchell, W., 1997: "The Interactions of Organizational and Competitive Influences on Strategy and Performance," Strategic Management Journal, 18, 5-14.

[31] Hicks, D., 1995: "Published Papers, Tacit Competencies and Corporate Management of the Public/Private Character of Knowledge," Industrial and Corporate Change, 4, 2, 410-424.

[32] Holmstrom, B., "Agency Costs and Innovation," Journal of Economic Behavior and Organization, 12, $3,305-327$.

[33] Holmstrom, B. and Milgrom, P., 1987: "Aggregation and Linearity in the Provision of Intertemporal Incentives," Econometrica, 55 303-328.

[34] Holmstrom, B. and Milgrom, P., 1994: "The Firm As An Incentive System," American Economic Review, 84, 4, 972-91.

[35] Huckman, R.S and Strick, E.P., 2010: "GlaxoSimithKline: Reorganizing Drug Discovery," Harvard Business School Case 9-605-074.

[36] Kling, J., 1998: "From Hypertension to Angina to Viagra," Modern Drug Discovery, 1, 2, 31-38. 
[37] Lakhani, K. von Hippel, E., 2003: "How Open Source Software Works: 'Free’ User-to-User Assistance," Research Policy, 32, 923-943.

[38] Lamoreaux, N.R. and Sokoloff, K.L., 1999: "Inventors, Firms, and the Market for Technology in the Late Nineteenth and Early Twentieth Centuries," in Lamoreaux, N.R., Raff, D.M.G. and Temin, P. (eds.), Learning By Doing in Firms, Markets, and Nations, The University of Chicago Press, 19-57.

[39] Lerner, J. and Wulf, J., 2006: "Innovation and Incentives: Evidence from Corporate R\&D," NBER Working Paper 11944.

[40] Lin, P. and Saggi, K., 2002: "Product Differentiation, Process R\&D, and the Nature of Market Competition," European Economic Review, 46, 201-211.

[41] Liu, C. and Stuart, T., 2010: "Boundary Spanning in a For-profit Research Lab: An Exploration of the Interface Between Commerce and Academe," Harvard Business School Working Paper 11-012.

[42] Manso, G., 2010: "Motivating Innovation," Journal of Finance, forthcoming.

[43] Merton, R.K. 1973: The Sociology of Science: Theoretical and Empirical Investigations, (edited by N.W. Storer), Univ. of Chicago Press.

[44] Mukherjee, A. and Stern, S., 2009: "Disclosure or Secrecy? The dynamics of Open Science", International Journal of Industrial Organization, 27, 449-462.

[45] Murdock, 2002: "Intrinsic Motivation and Optimal Incentive Contracts," RAND Journal of Economics, 33, 4, 650-671.

[46] Piccolo, S., D'Amato, M. and Martina, M., 2008: "Product Market Competition and Organizational Slack Under Profit-Target Contracts", International Journal of Industrial Organization, 26, 1389-1406

[47] Pietsch, T., 2006: "Serendipity: Or How the Drug Development Process Can Reverse Direction" Life Sciences Information Technology Global Institute, October.

[48] Porter, M., 1980: Competitive Strategy, Free Press.

[49] Qiu, L.D., 1997: "On the Dynamic Efficiency of Bertrand and Cournot Equilibria," Journal of Economic Theory, 75, 213-229.

[50] Raith, M., 2003: "Competition, Risk and Managerial Incentives," American Economic Review, 93, 1425-1436.

[51] Roach, M. and Sauermann, H., 2010: "A taste for science? PhD scientists' academic orientation and self-selection into research careers in industry," Research Policy, 39, 422-434.

[52] Rosenkranz, S., 2003: "Simultaneous Choice of Process and Product Innovation When Consumers Have a Preference for Product Variety," Journal of Economic Behavior and Organization, 50, 183-201. 
[53] Sacco, D. and Schmutzler, A., 2009: "Is There a U-shaped Relation between Competition and Innovation," International Journal of Industrial Organization, doi: 10.1016/j.ijindorg.2009.09.003.

[54] Sauermann, H. and Cohen, W., 2007: "Fire in the Belly? Individuals' Motives and Innovative Performance in Startups and Established Companies," working paper.

[55] Sauermann, H. and Cohen, W., 2010: "What Makes Them Tick? - Employee Motives and Industrial Innovation," Management Science, 65, 12, 2134-2153.

[56] Sauermann, H., Roach, M. and Zhang, W., 2010: "Is there a 'Taste for Science'? Scientists' Preferences and the Organization of Science," Georgia Institute of Technology working paper.

[57] Schmidt, K.M., 1997: "Managerial Incentives and Product Market Competition," Review of Economic Studies, 64, 191-213.

[58] Schumpeter, J., 1943: Capitalism, Socialism and Democracy, Allen Unwin.

[59] Schmutzler, A., 2010:"The relation between competition and innovation: why is it such a mess?," SOI Working Paper, University of Zurich.

[60] Singh, N. and Vives, X., 1984: "Price and Quantity Competition in a Differentiated Duopoly," RAND Journal of Economics, 15, 4, 546-554.

[61] Spence, M., 1984: "Cost Reduction, Competition and Industry Performance," Econometrica 52, 101121.

[62] Stern, S., 2004: "Do Scientists Pay to Be Scientists?," Management Science, 50, 6, 835-853.

[63] Turner, S.F., Mitchell, W. and Bettis, R.A., 2010: "Responding to Rivals and Complements: How Market Concentration Shapes Generational Product Innovation Strategy," Organization Science, 21, $854-872$.

[64] Vives, X., 2008: "Innovation and Competitive Pressure," Journal of Industrial Economics, 53, 3, 419469.

[65] Von Nordenflycht, A., 2007: "Is Public Ownership Bad for Professional Service Firms? Ad Agency Ownership, Performance and Creativity," Academy of Management Journal, 50, 2, 429-445.

[66] Williams, D., 2002: "Structure and Competition in the U.S. Home Video Game Industry," International Journal on Media Management, 4, 1, 41-54.

[67] Zucker, L. and Darby, M., 1995: "Virtuous Cycles of Productivity: Star Bioscientists and the Institutional Transformation of Industry," NBER Working Paper 5342. 


\section{A Notation and figures}

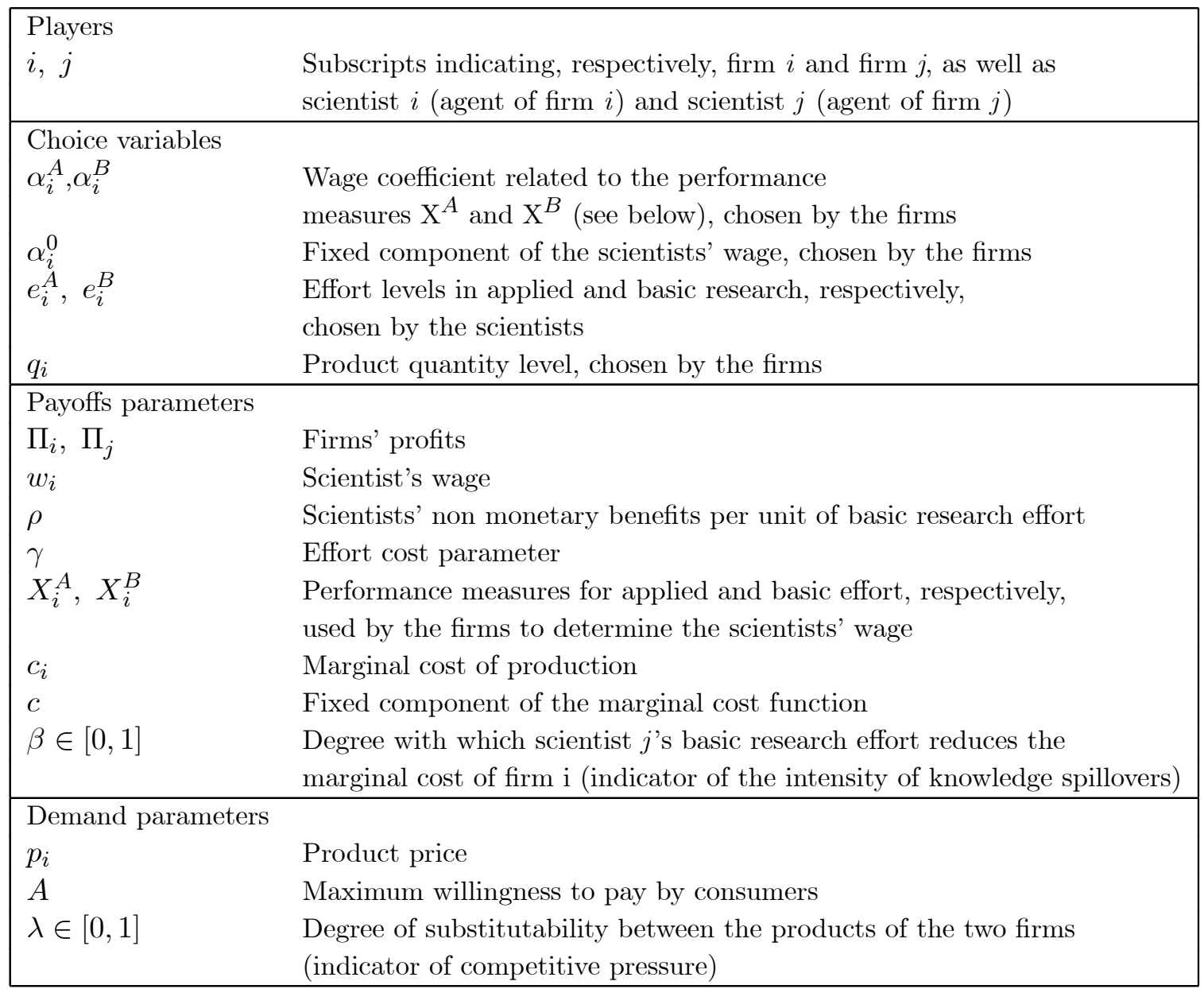

Table 1: Summary of the notation used in the model. The choice variables and parameters are reported only for firm i, for simplicity. 


\begin{tabular}{|c|c|c|c|}
\hline $\begin{array}{l}\mathrm{t}=1 \text { : firm } i \text { and } \\
\text { firm } j \text { propose a } \\
\text { wage contract }\left(\alpha^{9},\right. \\
\left.\alpha^{4}, \alpha^{B}\right) i \text { and }\left(\alpha^{0},\right. \\
\left.\alpha^{4}, \alpha^{B}\right) j \text { to } \\
\text { scientists } i \text { and } j, \\
\text { respectively }\end{array}$ & $\begin{array}{l}\mathrm{t}=2 \text { : the scientists } \\
\text { choose the amounts } \\
\text { of (non- } \\
\text { contractible) effort } \\
\left(e_{i}^{A}, e_{i}^{\bar{B}}\right) \text { and }\left(e_{j}^{A}, e_{j}^{\bar{B}}\right)\end{array}$ & $\begin{array}{l}\mathrm{t}=3 \text { : the } \\
\text { scientists } \\
\text { are paid }\end{array}$ & $\begin{array}{l}\mathrm{t}=4 \text { : firm } i \text { and } \\
\text { firm } j \text { compete on } \\
\text { the product } \\
\text { market, and } \\
\text { profits are realized }\end{array}$ \\
\hline
\end{tabular}

Figure 1: The game's timeline

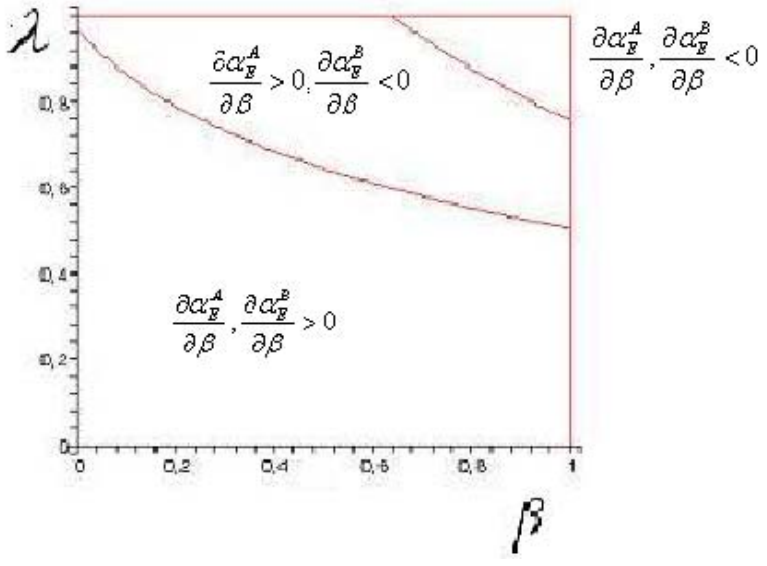

Figure 2: The impact of knowledge spillovers on the strength of incentives, for different combinations of knowledge spillovers and product market competition intensities. The examples are built using the following values: $A=2 ; c=1, \gamma=1.5, \rho=.2$. 


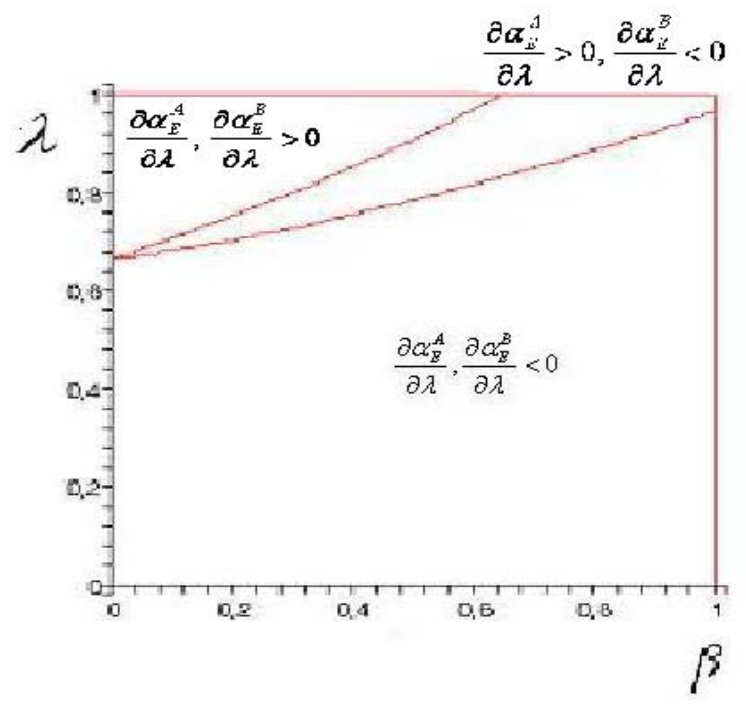

Figure 3: The impact of competitive pressure on the strength of incentives, for different combinations of knowledge spillovers and product market competition intensities. The examples are built using the following values: $A=2 ; c=1, \gamma=1.5, \rho=.2$.

\section{B Proofs}

Proof of Proposition 2.1 Substituting the constraints (11) and (12) and the profits $\Pi_{i}$ as expressed in $(10)$ - where in turn we plug in the marginal cost function $(3)$ - we obtain: ${ }^{15}$

$$
\begin{aligned}
E\left(T S_{i}\right)= & {\left[\frac{A}{\lambda+2}-\frac{2\left(c-\frac{\alpha_{i}^{A}}{\gamma}-\frac{\left(\rho+\alpha_{i}^{B}\right)}{\gamma}-\beta\left(\frac{\rho+\alpha_{j}^{B}}{\gamma}\right)\right)-\lambda\left(c-\frac{\alpha_{j}^{A}}{\gamma}-\frac{\left(\rho+\alpha_{j}^{B}\right)}{\gamma}-\beta \frac{\left(\rho+\alpha_{i}^{B}\right)}{\gamma}\right)}{(2-\lambda)(\lambda+2)}\right]^{2} } \\
& +\rho \frac{\left(\rho+\alpha_{i}^{B}\right)}{\gamma}-\frac{\left(\alpha_{i}^{A}\right)^{2}}{2 \gamma}-\frac{\left(\rho+\alpha_{i}^{B}\right)^{2}}{2 \gamma} .
\end{aligned}
$$

Invoking symmetry (i.e. $\alpha_{i}^{A}=\alpha_{j}^{A}$ and $\alpha_{i}^{B}=\alpha_{j}^{B}$ ) the first-order conditions become: ${ }^{16}$

$$
\begin{gathered}
\frac{\partial E(T S)}{\partial \alpha_{i}^{A}}=\left[A-c+\frac{\alpha_{i}^{A}}{\gamma}+\frac{(1+\beta)\left(\alpha_{i}^{B}+\rho\right)}{\gamma}\right]\left[\frac{4}{\gamma(2-\lambda)(2+\lambda)^{2}}\right]-\frac{\alpha_{i}^{A}}{\gamma}=0 ; \\
\frac{\partial E(T S)}{\partial \alpha_{i}^{B}}=\left[A-c+\frac{\alpha_{i}^{A}}{\gamma}+\frac{(1+\beta)\left(\alpha_{i}^{B}+\rho\right)}{\gamma}\right]\left[\frac{2(2-\beta \lambda)}{\gamma(2-\lambda)(2+\lambda)^{2}}\right]-\frac{\alpha_{i}^{B}}{\gamma}=0 .
\end{gathered}
$$

We assume that the second order conditions are satisfied. ${ }^{17}$ Solving the system of first order conditions and

\footnotetext{
${ }^{15}$ We shall assume that $\gamma>1$ to guarantee that (14) and (15) are always positive. Furthemore, in order to simplify the proof of one proposition below, we shall assume $A-c \geq \rho$.

${ }^{16}$ In equilibrium, $\alpha^{0}$ will be chosen for the scientist's participation constraint to bind.

${ }^{17}$ This requires: $\frac{\partial^{2} E(T S)}{\partial^{2} \alpha_{i}^{A}}=\frac{8}{(\gamma)^{2}(2-\lambda)^{2}(2+\lambda)^{2}}-\frac{1}{\gamma}<0 ; \frac{\partial^{2} E(T S)}{\partial^{2} \alpha_{i}^{B}}=\frac{2(2-\beta \lambda)^{2}}{(\gamma)^{2}(2-\lambda)^{2}(2+\lambda)^{2}}-\frac{1}{\gamma}<0 ;$ and $\frac{\partial^{2} E(T S)}{\partial^{2} \alpha_{i}^{A}} \frac{\partial^{2} E(T S)}{\partial^{2} \alpha_{i}^{B}}-$ $\left(\frac{\partial^{2} E(T S)}{\partial \alpha_{i}^{A} \alpha_{i}^{B}}\right)^{2}=\left[\frac{8}{\gamma^{2}(2-\lambda)^{2}(2+\lambda)^{2}}-\frac{1}{\gamma^{A}}\right]\left[\frac{2(2-\beta \lambda)^{2}}{\gamma^{2}(2-\lambda)^{2}(2+\lambda)^{2}}-\frac{1}{\gamma^{B}}\right]-\left[\frac{4(2-\beta \lambda)}{\gamma^{2}(2-\lambda)^{2}(2+\lambda)^{2}}\right]^{2}>0$.
} 
defining $k \equiv(\lambda+2)^{2}(2-\lambda)$, we obtain $\alpha_{E}^{A}$ and $\alpha_{E}^{A}$ as defined in (14) and (15) The fixed component of wage $\alpha^{0}$ is set so as teh scientists obtain their reservation utility $\bar{u}$.

Proof of Proposition 3.1 The proof is immediate from taking the ratio between the two equilibrium piece rates:

$$
\frac{\alpha_{E}^{A}}{\alpha_{E}^{B}}=\frac{2}{2-\beta \lambda}
$$

Proof of Proposition 3.2 and Corollary 3.2.1 If we differentiate $\alpha_{E}^{A}$ with respect to $\beta$, we obtain:

$$
\frac{\partial \alpha_{E}^{A}}{\partial \beta}=\frac{4 \rho[\gamma k-4-2(1+\beta)(2-\beta \lambda)]+8[\gamma(A-c)+\rho(1+\beta)][2-2 \beta \lambda-\lambda]}{[\gamma k-4-2(1+\beta)(2-\beta \lambda)]^{2}} .
$$

Notice that $[\gamma k-4-2(1+\beta)(2-\beta \lambda)]>0$ (since it is the denominator of $\alpha_{E}^{A}$ ), while $8[\gamma(A-c)+\rho \gamma(1+\beta)]$ $*(2-2 \beta \lambda-\lambda)$ is positive if $2-2 \beta \lambda-\lambda>0$. It follows that, if $\lambda<\frac{2}{1+2 \beta}$, then $\frac{\partial \alpha_{E}^{A}}{\partial \beta}>0$, from which the Corollary is obtained.

We now investigate the behavior of $\frac{\partial \alpha_{E}^{A}}{\partial \beta}$ as a function of $\lambda$. For $\lambda=0$ we know that $\frac{\partial \alpha_{E}^{A}}{\partial \beta}>0$. If we compute $\frac{\partial \alpha_{E}^{A}}{\partial \beta \partial \lambda}$ we obtain:

$$
\begin{aligned}
& \{4 \rho[\gamma(\lambda+2)(2-3 \lambda)-2(1+2 \beta) \beta]-8(A-c) \gamma(1+2 \beta)\} * \\
& {[\gamma k-4-2(1+\beta)(2-\beta \lambda)]^{2}} \\
& -\left\{8[\gamma(A-c)](2-2 \beta \lambda-\lambda)+4 \rho\left[\gamma k-4-2(1+\beta)^{2} \lambda\right]\right\} \\
& * 2[\gamma k-4-2(1+\beta)(2-\beta \lambda)] \\
& \frac{\partial \alpha_{E}^{A}}{\partial \beta \partial \lambda}=\frac{[\gamma(\lambda+2)(2-3 \lambda)+2(1+\beta) \beta]}{[\gamma k-4-2(1+\beta)(2-\beta \lambda)]^{4}} .
\end{aligned}
$$

Overall the sign is ambiguous, since the three quantities

$$
\begin{aligned}
& 4 \rho[\gamma(\lambda+2)(2-3 \lambda)-2(1+2 \beta) \beta]-8(A-c) \gamma(1+2 \beta), \\
& 8[\gamma(A-c)](2-2 \beta \lambda-\lambda)+4 \rho\left[\gamma k-4-2(1+\beta)^{2} \lambda\right], \text { and } \\
& {[\gamma(\lambda+2)(2-3 \lambda)+2(1+\beta) \beta]}
\end{aligned}
$$

all have ambiguous signs. However, when $\frac{\partial \alpha_{E}^{A}}{\partial \beta}=0$, the sign of $\frac{\partial \alpha_{E}^{A}}{\partial \beta \partial \lambda}$ is the sign of:

$$
\{4 \rho[\gamma(\lambda+2)(2-3 \lambda)-2(1+2 \beta) \beta]-8(A-c) \gamma(1+2 \beta)\}
$$

Expression (19) is negative for $\lambda \leq \frac{2}{3}$, which is a necessary condition to have $\frac{\partial \alpha_{E}^{A}}{\partial \beta}=0$. This implies that in any point in which the derivative is 0 , the graph cuts the horizontal axis "from above." In turn, together with $\frac{\partial \alpha_{E}^{A}}{\partial \beta}>0$ when $\lambda=0$, this implies that the value of $\lambda$ for which $\frac{\partial \alpha_{E}^{A}}{\partial \beta}=0$ is unique, if it exists. Then, there are two possible cases: i) $\frac{\partial \alpha_{E}^{A}}{\partial \beta}$ is first positive and then negative with respect to $\lambda$; ii) $\frac{\partial \alpha_{E}^{A}}{\partial \beta}$ is always positive. The first part of the Proposition follows from this. 
Define now $\lambda_{A}^{*}$ as the unique solution to $\frac{\partial \alpha_{E}^{A}}{\partial \beta}=0$. In order to show that $\lambda_{A}^{*}$ is decreasing in $\beta$, we can apply the implicit function theorem. Consider:

$$
H^{A}(\beta, \lambda)=32[\gamma(A-c)](2-2 \beta \lambda-\lambda)+16 \rho\left[\gamma k-4-2(1+\beta)^{2} \lambda\right]
$$

the solution of $H^{A}(\beta, \lambda)=0$ is the set of values for which $\frac{\partial \alpha_{E}^{A}}{\partial \beta}=0$. Denote with $\left(\lambda_{A}^{*}, \beta_{A}^{*}\right)$ a solution pair. Then, using the implicit function theorem, we can derive $\frac{\partial \lambda_{A}^{*}}{\partial \beta_{A}^{*}}$ as

$$
\frac{\partial \lambda_{A}^{*}}{\partial \beta_{A}^{*}}=-\frac{\left.\frac{\partial \alpha_{E}^{A}}{\partial \beta^{2}}\right|_{\frac{\partial \alpha_{E}^{A}}{\partial \beta}=0}}{\left.\frac{\partial \alpha_{E}^{A}}{\partial \beta \partial \lambda}\right|_{\frac{\partial \alpha_{E}^{A}}{\partial \beta}=0}} .
$$

We just showed that $\left.\frac{\partial \alpha_{E}^{A}}{\partial \beta \partial \lambda}\right|_{\frac{\partial \alpha_{E}^{A}}{\partial \beta}=0}<0$. As far as $\left.\frac{\partial \alpha_{E}^{A}}{\partial \beta^{2}}\right|_{\frac{\partial \alpha_{E}^{A}}{\partial \beta}=0}$ is concerned, differentiation yields:

$$
\begin{gathered}
\left\{\begin{array}{c}
-16 \lambda[\gamma(A-c)+(1+\beta) \rho]\}[\gamma k-4-2(1+\beta)(2-\beta \lambda)]^{2} \\
-\left\{8[\gamma(A-c)](2-2 \beta \lambda-\lambda)+4 \rho\left[\gamma k-4-2(1+\beta)^{2} \lambda\right]\right\} \\
\partial \beta^{2}
\end{array}=\frac{[2(2-2 \beta \lambda-\lambda)]}{* 2[\gamma k-4-2(1+\beta)(2-\beta \lambda)]}\right. \\
{[\gamma k-4-2(1+\beta)(2-\beta \lambda)]^{4}}
\end{gathered}
$$

whose sign, for $\frac{\partial \alpha_{E}^{A}}{\partial \beta}=0$, is the sign of $-16 \lambda[\gamma(A-c)+(1+\beta) \rho]$, which is negative. Then, $\frac{\partial \lambda_{A}^{*}}{\partial \beta_{A}^{*}}<0$, from which the second part of the Proposition follows.

Proof of Proposition 3.3 and Corollary 3.3.1 Differentiating $\alpha_{E}^{B}$ with respect to $\beta$, we obtain:

$$
\frac{\partial \alpha_{E}^{B}}{\partial \beta}=\frac{\begin{array}{c}
\{2 \rho(2-\beta \lambda)-2 \lambda[\gamma(A-c)+\rho(1+\beta)]\}[\gamma k-4-2(1+\beta)(2-\beta \lambda)] \\
+4[\gamma(A-c)+\rho(1+\beta)](2-2 \beta \lambda-\lambda)(2-\beta \lambda)
\end{array}}{[\gamma k-4-2(1+\beta)(2-\beta \lambda)]^{2}}
$$

whose sign is ambiguous. However, if $(2-2 \beta \lambda-\lambda)<0$ (i.e., $\left.\lambda>\frac{2}{1+2 \beta}\right)$, then $\frac{\partial \alpha_{E}^{B}}{\partial \beta}<0$. To see this, notice that $\{2 \rho(2-\beta \lambda)-2 \lambda[\gamma(A-c)+\rho(1+\beta)]\}$ is equal to $\frac{\rho \beta-\beta-\gamma(A-c)-\rho(1+\beta)}{1+2 \beta}<0$ for $\lambda=\frac{2}{1+2 \beta}$, and then is a fortiori negative for $\lambda<\frac{2}{1+2 \beta}$. Therefore, since $\frac{\partial \alpha_{E}^{B}}{\partial \beta}$ is the sum of two negative quantities, the Corollary follows.

We study now the behavior of $\frac{\partial \alpha_{E}^{B}}{\partial \beta}$ as a function of $\lambda$. For $\lambda=0$, we have $\frac{\partial \alpha_{E}^{B}}{\partial \beta}>0$. Differentiating, we obtain:

$$
\begin{aligned}
& \left\{\begin{array}{c}
2 \rho[(-2 \beta-1)(\gamma k-4)+(2-2 \beta \lambda-\lambda) \gamma(\lambda+2)(2-3 \lambda)] \\
-2 \gamma(A-c)[\gamma k-4+\lambda(\lambda+2)(2-3 \lambda)+4 \beta(2-\beta \lambda)]
\end{array}\right\} * \\
& {[\gamma k-4-2(1+\beta)(2-\beta \lambda)]^{2}} \\
& -2 \rho(2-2 \beta \lambda-\lambda)(\gamma k-4)-2 \gamma(A-c)\left[\lambda(\gamma-4)-2(2-\beta \lambda)^{2}\right] * \\
& 2[\gamma k-4-2(1+\beta)(2-\beta \lambda)] * \\
& \frac{\partial \alpha_{E}^{B}}{\partial \beta \partial \lambda}=\frac{[(\lambda+2)(2-3 \lambda)+2(1+\beta) \beta]}{[\gamma k-4-2(1+\beta)(2-\beta \lambda)]^{4}} .
\end{aligned}
$$


The sign of (21) is ambiguous. However, we prove that $\frac{\partial \alpha_{E}^{B}}{\partial \beta \partial \lambda}<0$ when $\frac{\partial \alpha_{E}^{B}}{\partial \beta}=0$. In this case, the sign of $\frac{\partial \alpha_{E}^{B}}{\partial \beta \partial \lambda}$ is the sign of:

$$
\left\{\begin{array}{c}
2 \rho[(-2 \beta-1)(\gamma k-4)+(2-2 \beta \lambda-\lambda) \gamma(\lambda+2)(2-3 \lambda)] \\
-2 \gamma(A-c)[\gamma k-4+\lambda(\lambda+2)(2-3 \lambda)+4 \beta(2-\beta \lambda)]
\end{array}\right\}
$$

Notice, from above considerations, that in order to have $\frac{\partial \alpha_{E}^{B}}{\partial \beta}=0$, it must be $(2-2 \beta \lambda-\lambda)>0$. Then if $(2-3 \lambda)<0$, the above quantity is negative, and the proof is given. Assume instead that $(2-3 \lambda)>0$ and that $[(-2 \beta-1)(\gamma k-4)+(2-2 \beta \lambda-\lambda) \gamma(\lambda+2)(2-3 \lambda)]>0$ (which would otherwise imply that (22) is negative). By assumption, $A-c \geq \rho$. Thus, if

$\gamma[\gamma k-4+\lambda(\lambda+2)(2-3 \lambda)+4 \beta(2-\beta \lambda)]>(-2 \beta-1)(\gamma k-4)+(2-2 \beta \lambda-\lambda) \gamma(\lambda+2)(2-3 \lambda)$, then we proved our result. Simplifying the expression, we obtain:

$$
(\gamma+1+2 \beta)(\gamma k-4)-\gamma(\lambda+2)(2-3 \lambda)(2-2 \beta \lambda)+4 \beta \gamma(2-\beta \lambda)>0
$$

We note the following. $(\gamma+1+2 \beta)$ is increasing in $\beta$. $(\gamma k-4)$ is increasing in $\lambda$ when $\lambda<\frac{2}{3}$. $(\lambda+2)(2-3 \lambda)(2-2 \beta \lambda)>$ is decreasing in $\lambda$ since $\frac{\partial(\lambda+2)(2-3 \lambda)}{\partial \lambda}=2-3 \lambda-3 \lambda-6<0$, and is decreasing in $\beta$. Finally, $\frac{\partial 4 \beta \gamma(2-\beta \lambda)}{\partial \beta}=$ $\gamma(2-2 \beta \lambda)>0$, since $(2-2 \beta \lambda-\lambda)>0$. This implies that if (23) is positive for $\beta=\lambda=0$, then our claim follows. For $\beta=\lambda=0,(\gamma+1)(8 \gamma-4)-8 \gamma>0$, since $\gamma>1$.

We proved that $\frac{\partial \alpha_{E}^{B}}{\partial \beta \partial \lambda}<0$ when $\frac{\partial \alpha_{E}^{B}}{\partial \beta}=0$. This means that, in any point in which the derivative is 0 , the graph cuts "from above" the horizontal axis. In turn, together with $\frac{\partial \alpha_{E}^{B}}{\partial \beta}>0$ in $\lambda=0$, this implies that the value of $\lambda$ for which $\frac{\partial \alpha_{E}^{B}}{\partial \beta}=0$ is unique, if existing. Then, there are two possible cases: i) $\frac{\partial \alpha_{E}^{B}}{\partial \beta}$ is first positive and then negative with respect to $\lambda$; ii) $\frac{\partial \alpha_{E}^{B}}{\partial \beta}$ is always positive. The first part of the Proposition follows.

Define $\lambda_{B}^{*}$ as the unique solution to $\frac{\partial \alpha_{E}^{B}}{\partial \beta}=0$. In order to show that $\lambda_{B}^{*}$ is decreasing in $\beta$, we can apply, again, the implicit function theorem. Consider:

$$
H^{B}(\beta, \lambda)=2 \rho(2-2 \beta \lambda-\lambda)(\gamma k-4)-2 \gamma(A-c)\left[\lambda(\gamma-4)-2(2-\beta \lambda)^{2}\right]
$$

the solution of $H^{B}(\beta, \lambda)=0$ is the set of values for which $\frac{\partial \alpha_{E}^{B}}{\partial \beta}=0$. Denote with $\left(\lambda_{B}^{*}, \beta_{B}^{*}\right)$ a solution pair. Then, using the implicit function theorem, we derive $\frac{\partial \lambda_{B}^{*}}{\partial \beta_{B}^{*}}$ :

$$
\frac{\partial \lambda_{B}^{*}}{\partial \beta_{B}^{*}}=-\frac{\left.\frac{\partial \alpha_{E}^{B}}{\partial \beta^{2}}\right|_{\frac{\partial \alpha_{E}^{B}}{\partial \beta}=0}}{\left.\frac{\partial \alpha_{E}^{B}}{\partial \beta \partial \lambda}\right|_{\frac{\partial \alpha_{E}^{B}}{\partial \beta}=0}} .
$$

We just showed that $\left.\frac{\partial \alpha_{E}^{B}}{\partial \beta^{2}}\right|_{\frac{\partial \alpha_{E}^{B}}{\partial \beta}=0}<0$. As for $\left.\frac{\partial \alpha_{E}^{B}}{\partial \beta^{2}}\right|_{\frac{\partial \alpha_{E}^{B}}{\partial \beta}=0}$, computing $\frac{\partial^{2} \alpha_{E}^{B}}{\partial \beta^{2}}=0$ we obtain:

$$
\frac{\partial^{2} \alpha_{E}^{B}}{\partial \beta^{2}}=\frac{\begin{array}{c}
{[-4 \rho \lambda(\gamma k-4)-4 \lambda \gamma(A-c)(2-\beta \lambda)][\gamma k-4-2(1+\beta)(2-\beta \lambda)]^{2}+} \\
{\left[2 \rho(2-2 \lambda \beta-\lambda)(\gamma k-4)-2 \gamma(A-c)\left(\lambda(\gamma k-4)-2(2-\beta \lambda)^{2}\right]^{*}\right.} \\
2(\gamma k-4-2(1+\beta)(2-\beta \lambda))(2(2-2 \beta \lambda-\lambda))
\end{array}}{[\gamma k-4-2(1+\beta)(2-\beta \lambda)]^{4}} .
$$


If $\frac{\partial \alpha_{E}^{B}}{\partial \beta}=0$, then the sign of $\frac{\partial^{2} \alpha_{E}^{B}}{\partial \beta^{2}}$ is the sign of $[-4 \rho \lambda(\gamma k-4)-4 \lambda \gamma(A-c)(2-\beta \lambda)]$, which is always negative. The second part of the Proposition follows. Finally, to show that $\lambda_{B}^{*} \leq \lambda_{A}^{*}$ note that for $2-2 \beta \lambda-\lambda=0, \frac{\partial \alpha_{E}^{A}}{\partial \beta}>0$, which implies $\lambda_{A}^{*}>\frac{2}{1+2 \beta}$, and $\frac{\partial \alpha_{E}^{B}}{\partial \beta}<0$, which implies $\lambda_{B}^{*}<\frac{2}{1+2 \beta}$.

Proof of Proposition 3.4 Differentiating $\alpha_{E}^{A}$ with respect to $\lambda$, we obtain:

$$
\frac{\partial \alpha_{E}^{A}}{\partial \lambda}=-\frac{4[\gamma(A-c)+\rho(1+\beta)][\gamma(\lambda+2)(2-3 \lambda)+2(1+\beta) \beta]}{[\gamma k-4-2(1+\beta)(2-\beta \lambda)]^{2}},
$$

which has the same sign as $-[\gamma(\lambda+2)(2-3 \lambda)+2(1+\beta) \beta]$. Consequently, we have $\frac{\partial \alpha_{E}^{A}}{\partial \lambda}>0$ if $\lambda>\frac{\sqrt{16+\frac{6 \beta(1+\beta)}{\gamma}}-2}{3}=\lambda_{A}^{* *}$. It is immediate to verify that $\lambda_{A}^{* *}$ is increasing in $\beta$. Notice that it also possible that the derivative is always negative. This occurs when $\sqrt{16+6 \frac{\beta(1+\beta)}{\gamma}}-2>3$, i.e., $\gamma<\frac{2}{3} \beta(1+\beta)$.

Proof of Proposition 3.5 Differentiating $\alpha_{E}^{B}$ with respect to $\lambda$, we obtain:

$$
\frac{\partial \alpha_{E}^{B}}{\partial \lambda}=\frac{2[\gamma(A-c)+\rho(1+\beta)]\left\{\begin{array}{c}
-\beta[\gamma k-4-2(1+\beta)(2-\beta \lambda)] \\
-(2-\beta \lambda)[\gamma(\lambda+2)(2-3 \lambda)+2(1+\beta) \beta]
\end{array}\right\}}{[\gamma k-4-2(1+\beta)(2-\beta \lambda)]^{2}},
$$

which can be simplified to:

$$
\frac{\partial \alpha_{E}^{B}}{\partial \lambda}=\frac{8[\gamma(A-c)+\rho(1+\beta)]\{-\beta(\gamma k-4)-(2-\beta \lambda) \gamma(\lambda+2)(2-3 \lambda)\}}{[\gamma k-4-2(1+\beta)(2-\beta \lambda)]^{2}} .
$$

We study now the sign of $\frac{\partial \alpha_{E}^{B}}{\partial \lambda}$ as a function of $\lambda$. From (28), we have $\frac{\partial \alpha_{E}^{B}}{\partial \lambda}<0$ in $\lambda=0$. Computing $\frac{\partial^{2} \alpha_{E}^{B}}{\partial \lambda^{2}}$ we obtain:

$$
\frac{\partial^{2} \alpha_{E}^{B}}{\partial \lambda^{2}}=\frac{2[\gamma(A-c)+\rho(1+\beta)]\left\{\begin{array}{c}
{[-\gamma(2-\beta \lambda)(-4-6 \lambda)][\gamma k-4-2(1+\beta)(2-\beta \lambda)]^{2}-} \\
{[-\beta(\gamma k-4)-(2-\beta \lambda) \gamma(\lambda+2)(2-3 \lambda)] *} \\
2[\gamma k-4-2(1+\beta)(2-\beta \lambda)] * \gamma(\lambda+2)(2-3 \lambda)+2(1+\beta) \beta
\end{array}\right\}}{[\gamma k-4-2(1+\beta)(2-\beta \lambda)]^{4}}
$$

If $\frac{\partial \alpha_{E}^{B}}{\partial \lambda}=0$, the sign of $\frac{\partial^{2} \alpha_{E}^{B}}{\partial \lambda^{2}}$ is the sign of $-\gamma(2-\beta \lambda)(-4-6 \lambda)$, then $\frac{\partial^{2} \alpha_{E}^{B}}{\partial \lambda^{2}}>0$. Then, in any point in which the derivative is 0 , the graph cuts from "below" the horizontal axis. This implies that the value of $\lambda$ for which $\frac{\partial \alpha_{E}^{B}}{\partial \lambda}=0$ is unique, if existing. Then, there are two possible cases: i) $\frac{\partial \alpha_{E}^{B}}{\partial \lambda}=0$ is first negative, then positive; ii) $\frac{\partial \alpha_{E}^{B}}{\partial \lambda}=0$ is always negative. The first part of Proposition follows.

In order to show that $\lambda_{B}^{* *}$ is increasing in $\beta$, the implicit function theorem is applied again. Consider:

$$
W^{B}(\beta, \lambda)=\{-\beta(\gamma k-4)-(2-\beta \lambda) \gamma(\lambda+2)(2-3 \lambda)\}
$$

the solution of $W^{B}(\beta, \lambda)=0$ is the set of values for which $\frac{\partial \alpha_{E}^{B}}{\partial \lambda}=0$. Denote with $\left(\lambda_{B}^{* *}, \beta_{B}^{* *}\right)$ a solution pair. Then, using the implicit function theorem, we derive $\frac{\partial \lambda_{B}^{* *}}{\partial \beta_{B}^{* *}}$ : 


$$
\frac{\partial \lambda_{B}^{* *}}{\partial \beta_{B}^{* *}}=-\frac{\left.\frac{\partial \alpha_{E}^{B}}{\partial \lambda \partial \beta}\right|_{\frac{\partial \alpha_{E}^{B}}{\partial \lambda}=0}}{\left.\frac{\partial \alpha_{E}^{B}}{\partial^{2} \lambda}\right|_{\frac{\partial \alpha_{E}^{B}}{\partial \lambda}=0}}
$$

Thus, $\left.\frac{\partial \alpha_{E}^{B}}{\partial \lambda^{2}}\right|_{\frac{\partial \alpha_{E}^{B}}{\partial \lambda}=0}>0$. Regarding $\left.\frac{\partial \alpha_{E}^{B}}{\partial \lambda \partial \beta}\right|_{\frac{\partial \alpha_{E}^{B}}{\partial \lambda}=0}$, we obtain:

$$
\left.\begin{array}{c}
\left\{\begin{array}{c}
2[\gamma(A-c)+\rho(1+\beta)][-\gamma k+\lambda \gamma(\lambda+2)(2-3 \lambda)] \\
+2 \rho[-\beta(\gamma k-4)-(2-\beta \lambda) \gamma(\lambda+2)(2-3 \lambda)]
\end{array}\right\} * \\
{[\gamma k-4-2(1+\beta)(2-\beta \lambda)]^{2}+}
\end{array}\right) .
$$

When $\frac{\partial \alpha_{E}^{B}}{\partial \lambda}=0$, the sign of $\frac{\partial \alpha_{E}^{B}}{\partial \lambda \partial \beta}$ is the sign of $[-\gamma k+\lambda \gamma(\lambda+2)(2-3 \lambda)]$. After some manipulations we obtain:

$$
[-\gamma k+\lambda \gamma(\lambda+2)(2-3 \lambda)]=-\gamma(\lambda+2)\left(4-4 \lambda^{2}+2 \lambda\right)<0,
$$

from which the Proposition follows.

Finally, in order to show that $\lambda_{B}^{* *} \leq \lambda_{A}^{* *}$, we show that, if $\frac{\partial \alpha_{E}^{A}}{\partial \lambda}<0$, then $\frac{\partial \alpha_{E}^{B}}{\partial \lambda}<0$, which in turn implies the claim. In fact, if $\frac{\partial \alpha_{E}^{A}}{\partial \lambda}<0$, then $[\gamma(\lambda+2)(2-3 \lambda)+2(1+\beta) \beta]>0$, which from (27) implies $\frac{\partial \alpha_{E}^{B}}{\partial \lambda}<0$. We have $\lambda_{B}^{* *}=\lambda_{A}^{* *}$ when $\beta=0$.

Proof of Proposition 3.6 If we compute the cross-derivatives of the total surplus function TS with respect to $\lambda$, we obtain:

$$
\begin{aligned}
\frac{\partial^{2} E(T S)}{\partial \alpha_{i}^{A} \partial \lambda} & =\frac{\partial q_{i}}{\partial \lambda} \frac{4}{\gamma(\lambda+2)(\lambda-2)}+\frac{q_{i}}{\gamma} \frac{8 \lambda}{\left(4-\lambda^{2}\right)^{2}}>0 \\
\frac{\partial^{2} E(T S)}{\partial \alpha_{i}^{B} \partial \lambda} & =\frac{\partial q_{i}}{\partial \lambda} \frac{2(2-\beta \lambda)}{\gamma(\lambda+2)(\lambda-2)}+\frac{q_{i}}{\gamma}\left[\frac{8(\lambda-\beta)-2 \lambda^{2} \beta}{\left(4-\lambda^{2}\right)^{2}}\right]>0 .
\end{aligned}
$$

Under symmetry $\left(c_{i}=c_{j}\right)$, we get $\frac{\partial q_{i}}{\partial \lambda}=-\frac{\left(A-c_{i}\right)}{(\lambda+2)^{2}}$ and $q_{i}=\frac{\left(A-c_{i}\right)}{(\lambda+2)}$. Then, supermodularity holds if:

$$
\begin{gathered}
2 \lambda>2-\lambda \\
{\left[4(\lambda-\beta)-\lambda^{2} \beta\right]>(2-\beta \lambda)(2-\lambda)}
\end{gathered}
$$

The first inequality is satisfied if $\lambda>\frac{2}{3}$. As for the second inequality, we define:

$$
Z(\lambda, \beta)=4(\lambda-\beta)-\lambda^{2} \beta-(2-\beta \lambda)(2-\lambda)
$$

and we obtain: 


$$
\begin{aligned}
\frac{\partial Z(\beta, \lambda)}{\partial \lambda} & =4-2 \lambda \beta+\beta(2-\lambda)+(2-\beta \lambda)>0 ; \\
\left.Z(\lambda, \beta)\right|_{\beta=0} & =6 \lambda-4 ; \text { and } \\
\frac{\partial \lambda}{\partial \beta} & =\frac{2-\lambda+\lambda^{2}}{3+\beta-2 \beta \lambda}>0,
\end{aligned}
$$

where $\frac{\partial \lambda}{\partial \beta}$ is obtained using Dini's theorem on the implicit function $Z(\lambda, \beta)$. These results together imply that $\frac{\partial^{2} E(T S)}{\partial \alpha_{i}^{B} \partial \lambda}>0$ when $\lambda>\underline{\lambda}(\beta)$, with $\underline{\lambda}(\beta) \geq \frac{2}{3}$ and $\frac{d \underline{\lambda}(\beta)}{d \beta}>0$. Since this condition is stricter than $\lambda>\frac{2}{3}$, we can derive the claim.

Proof of Proposition 3.7 From (17) and (18), respectively, we obtain, after invoking symmetry:

$$
\begin{aligned}
\frac{\partial^{2} E(T S)}{\partial \alpha_{i}^{A} \partial \beta} & =\frac{\left(\alpha_{i}^{B}+\rho\right)}{(\lambda+2)^{2}(2-\lambda)} \frac{4}{\gamma} \geq 0 \\
\frac{\partial^{2} E(T S)}{\partial \alpha_{i}^{B} \partial \beta} & =\frac{\left(\alpha_{i}^{B}+\rho\right)}{(\lambda+2)^{2}(2-\lambda)}\left[\frac{2(2-\beta \lambda)}{\gamma}\right]-q_{i}\left[\frac{2 \lambda}{\gamma(2-\lambda)(2+\lambda)}\right] .
\end{aligned}
$$

For $\lambda \rightarrow 0,(32)$ is positive, so that we have the claim.

Proof of Proposition 3.8 The proof is immediate by inspection of the expressions (14) and (15), since $\rho$ appears only in the two numerators, which are both increasing in $\rho$. We can also see that:

$$
\begin{aligned}
& \frac{\partial E(T S)}{\partial \alpha_{i}^{A} \partial \rho}=2\left[\frac{1+\beta}{\gamma(2+\lambda)}\right]\left[\frac{2}{\gamma(2-\lambda)(2+\lambda)}\right]>0 \\
& \frac{\partial E(T S)}{\partial \alpha_{i}^{B} \partial \rho}=2\left[\frac{1+\beta}{\gamma(2+\lambda)}\right]\left[\frac{2-\beta \lambda}{\gamma(2-\lambda)(2+\lambda)}\right]>0 .
\end{aligned}
$$

Proof of Proposition 3.9 In equilibrium, the agent's participation constraint binds:

$$
E\left(U_{i}\right)=\alpha_{E}^{0}+\alpha_{E}^{A}\left(\frac{\alpha_{E}^{A}}{\gamma}\right)+\alpha_{E}^{B}\left(\frac{\alpha_{E}^{B}+\rho}{\gamma}\right)+\rho\left(\frac{\alpha_{E}^{B}+\rho}{\gamma}\right)-\frac{\gamma\left(\frac{\alpha_{E}^{A}}{\gamma}\right)^{2}}{2}-\frac{\gamma\left(\frac{\alpha_{E}^{B}+\rho}{\gamma}\right)^{2}}{2}=\bar{u},
$$

where the equilibrium values for efforts are substituted into the expression. Simplifying the expression, we are left with:

$$
E\left(U_{i}\right)=\alpha_{E}^{0}+\frac{\left(\alpha_{E}^{A}\right)^{2}}{2 \gamma}+\frac{\left(\alpha_{E}^{B}\right)^{2}}{2 \gamma}+\frac{\rho^{2}}{2 \gamma}+\frac{\rho \alpha_{E}^{B}}{\gamma} .
$$

The quantity $\frac{\left(\alpha_{E}^{A}\right)^{2}}{2 \gamma}+\frac{\left(\alpha_{E}^{B}\right)^{2}}{2 \gamma}+\frac{\rho^{2}}{2 \gamma}+\frac{\rho \alpha_{E}^{B}}{\gamma}$ is increasing in $\rho$ since all its terms are increasing in $\rho$. As a consequence, $\alpha_{E}^{0}$, the fixed component of wage, is decreasing in $\rho$ in order for $E\left(U_{i}\right)$ to be constant. 
Proof of Proposition 3.10 In equilibrium, $E(w)=\bar{u}+\frac{\left(\alpha_{E}^{A}\right)^{2}}{2 \gamma}+\frac{\left(\alpha_{E}^{B}\right)^{2}}{2 \gamma}-\frac{\rho^{2}}{2 \gamma}$. Differentiating with respect to $\rho$, we get $\frac{\partial E(w)}{\delta \rho}=\frac{\partial \alpha_{E}^{A}}{\partial \rho} \frac{\alpha_{E}^{A}}{\gamma}+\frac{\partial \alpha_{E}^{B}}{\partial \rho} \frac{\alpha_{E}^{B}}{\gamma}-\frac{\rho}{\gamma}$, which is positive for $\rho \rightarrow 0$. An example for which $\frac{\partial E(w)}{\partial \rho}$ is always increasing in $\rho$ is $A=2, c=1, \lambda=1, \beta=0.5, \gamma=1.5, \bar{u}=0$ from which we get $\frac{\partial E(w)}{\partial \rho}=1.5+0.833 \rho$. An example for which $\frac{\partial E(w)}{\partial \rho}$ is decreasing in $\rho$ for high $\rho$ is $A=2, c=1, \lambda=0.2, \beta=0.5, \gamma=5, \bar{u}=0$ from which we get $\frac{\partial E(w)}{\partial \rho}=0.0398-0.188 \rho$. 